\title{
Fractionation of grain size in terrestrial sediment routing systems
}

Philip A. Allen, Nikolaos A. Michael, Mitchall D’Arcy, Duna C. Roda-Boluda, Alexander C. Whittaker, Robert A. Duller, John J. Armitage

\section{Abstract}

Sediment is fractionated by size during its cascade from source to sink in sediment routing systems. It is anticipated, therefore, that the grain size distribution of sediment will undergo down-system changes as a result of fluvial sorting processes and selective deposition. We assess this hypothesis by comparing grain size statistical properties of samples from within the erosional source region with those that have undergone different amounts of transport. A truncated Pareto distribution describes well the coarser half of the clast size distribution of regolith, coarse channel bed sediment and proximal debris flows (particularly their levees), as well as the coarser half of the clast size distribution of gravels that have undergone considerable amounts of transport in rivers. The Pareto shape parameter a evolves in response to mobilization, sediment transport and, importantly, the selective extraction of particles from the surface flow to build underlying stratigraphy. A goodness of fit statistic, the Kolmogorov-Smirnov vertical difference, illustrates the closeness of the observed clast size distributions to the Pareto,

Weibull and log-normal models as a function of distance from the depositional apex. The goodness of fit of the particle size distribution of regolith varies with bedrock geology. Bedload sediment at catchment outlets is fitted well by the log-normal and truncated Pareto models, whereas the exponential Weibull model provides a less good fit. In the Eocene Escanilla palaeo-sediment routing system of the 
south-central Pyrenees, the log-normal and truncated Pareto models provide excellent fits for distances of up to $80 \mathrm{~km}$ from the depositional apex, whereas the Weibull fit progressively worsens with increasing transport distance. A similar trend is found in the Miocene-Pliocene gravels of the Nebraskan Great Plains over a distance of $>300 \mathrm{~km}$. Despite the large fractionation in mean grain size and gravel percentage from source region to depositional sink, particle size distributions therefore appear to maintain log-normality over a wide range of transport distance. Use of statistical models enables down-system fractionation of sediment released from source regions to be better understood and predicted and is a potentially valuable tool in source-to-sink approaches to basin analysis.

\section{Introduction}

Upon release from upstream catchments, sediment cascades through the sediment routing system en route to depositional sinks (Burt \& Allison, 2010; Allen \& Allen, 2013). During down-system dispersal, the sediment is fractionated by its size, principally by the selective deposition of relatively large particles from the overlying flow (Seal et al., 1997; Fedele \& Paola, 2007). This down-system fractionation controls a wide range of morphometric, sedimentological and stratigraphic characteristics (Strong et al., 2005), such as the grain sizes in river channels, banks and floodplains that influence fluvial style and the evolution of meandering, the porosity-permeability of subsurface aquifers and hydrocarbon reservoirs, the grade of sediment received by deltas and their submarine clinoforms, and ultimately the flux and calibre of sediment delivered to the deep sea. At present, little is known of the impact of variations in the grain size distribution of the sediment supply on down-system fractionation, and relatively few studies have been carried out that quantitatively document grain size trends in geological examples of sediment routing systems (Paola et al., 1992; Robinson \& Slingerland, 1998; Duller et al., 2010; Whittaker et al., 2010; Carvajal \& Steel, 2012; Paola \& Martin, 2012; Michael et al., 2013, 2014; Hampson et al., 2014). One way of tackling this challenging problem is to record the statistical properties of grain size distributions of sediment found within the erosional and depositional realms of modern and ancient sediment routing systems.

It is generally recognized that there is a paucity of information on the grain size distributions of the weathering products that define the initial condition for sediment dispersal (Weltje, 2012). The crystal size distribution in crystalline parent rocks, for example, has been described as log-normal (Eberl et al., 1998), but it is not known whether this is a general rule for other rock types and in regolith comprising rock fragments and broken particles rather than individual mineralogical crystals. The size distribution of weathered crystalline rocks such as granites, which have undergone brittle disintegration, has also been found to be approximated by Rosin's (exponential) law (Krumbein \& Tisdel, 1940; McEwen et al., 1959). Crushed materials and those undergoing mechanical disintegration such as scree, regolith (including on moons and other planets), pyroclastic material and subglacial tills have also been described by the Rosin law (Kittleman, 1964; Ibbeken, 1983; Deb \& Sen, 2013). and the closely related Weibull distribution. Other workers have argued that materials that have undergone comminution commonly have a fractal distribution of size (Hartmann, 1969; Turcotte, 1997; Smalley et al., 2005; Allen et al., 2015). There is therefore considerable uncertainty about the size distribution of the rock fragments comprising the starting material for sediment. Nor is it clear what changes take place in the grain size distribution of sediment as it is mobilized from regolith, transported and sorted by hydraulic processes and eventually selectively extracted from the surface flux and transferred to the substrate. These various processes are likely to have a multiplicative effect (Dacey \& Krumbein, 1979).

McEwen et al . (1959) suggested that processes associated with transport such as abrasion and fracturing caused the grain size distribution to be modified, stating that (p. 492) 'The cumulative effect of the various agents and processes acting on the sediment after its formation will, in general, impose a lognormal size distribution on the sediment'. If this were the case, it would be in agreement with the long-held view that the size distribution of transported sediments is commonly log-normal (Krumbein, 1938). 
Exponential distributions such as the Rosin and Weibull 'laws' have a sigmoidal cumulative distribution function that is close to a fractal (power law) approximation at small values of the linear dimension $x$, which in this case is grain size (Fig. 1). The Pareto distribution, which is also closely associated with fractals, is thought to describe well the effects of fragmentation. The Pareto distribution shows increasing probabilities as the length dimension approaches a finite minimum value, which is reflected in a distinctive cumulative distribution function (Fig. 2). The log-normal distribution, on the other hand, has a peak in the probability distribution function at $x>0$ that depends on the covariance (standard deviation/mean, $\sigma / \mu$ ) (Fig. 3). The probability and cumulative distribution functions of the three statistical models are compared in Fig. 4.

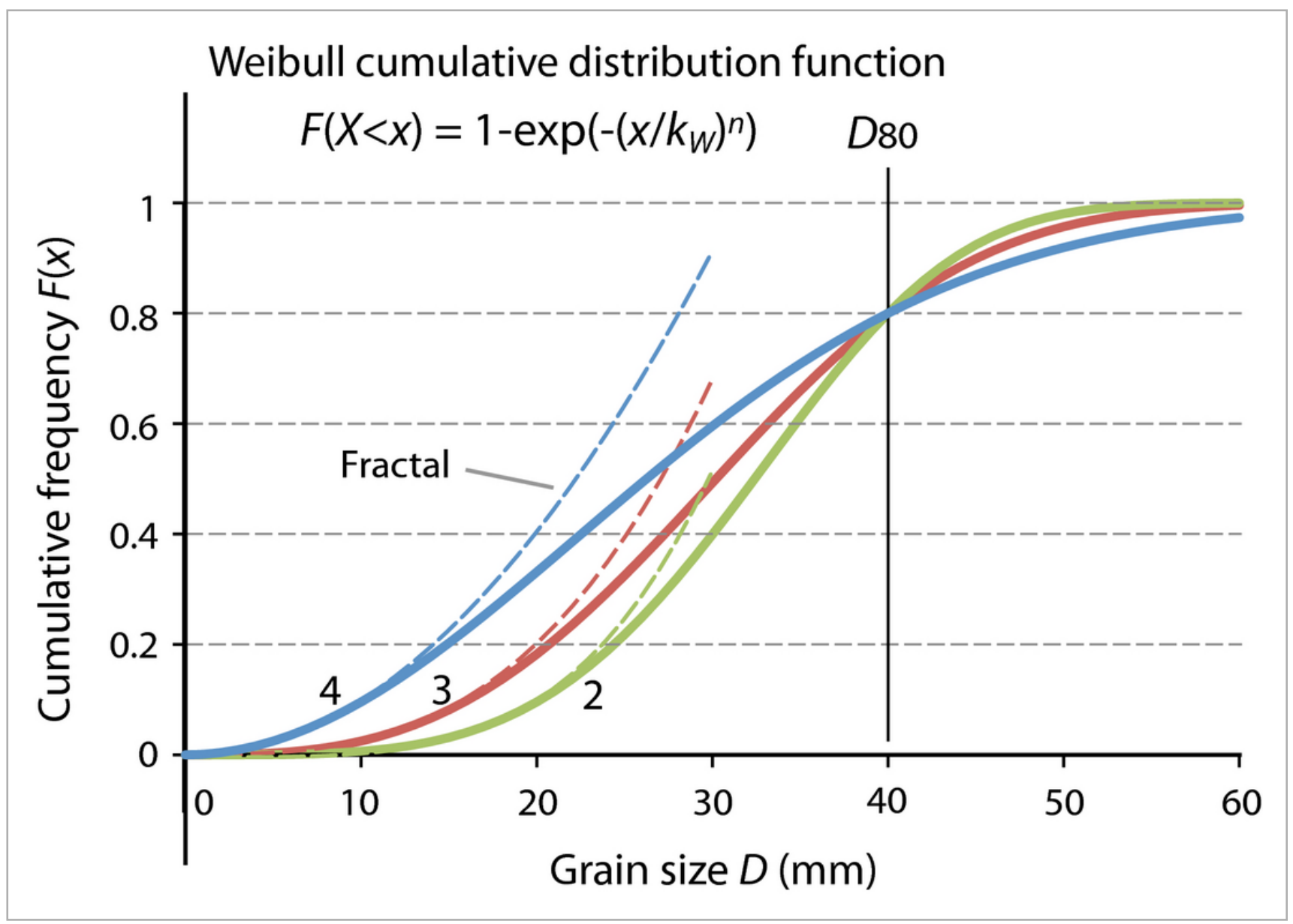

\section{Figure 1.}

Open in figure viewer

Weibull distribution for values of the exponent $n$ of 2, 3 and 4, with the fractal approximation shown at low values of grain size. Each curve has a reference grain size $D_{80}$ of $40 \mathrm{~mm}$. 


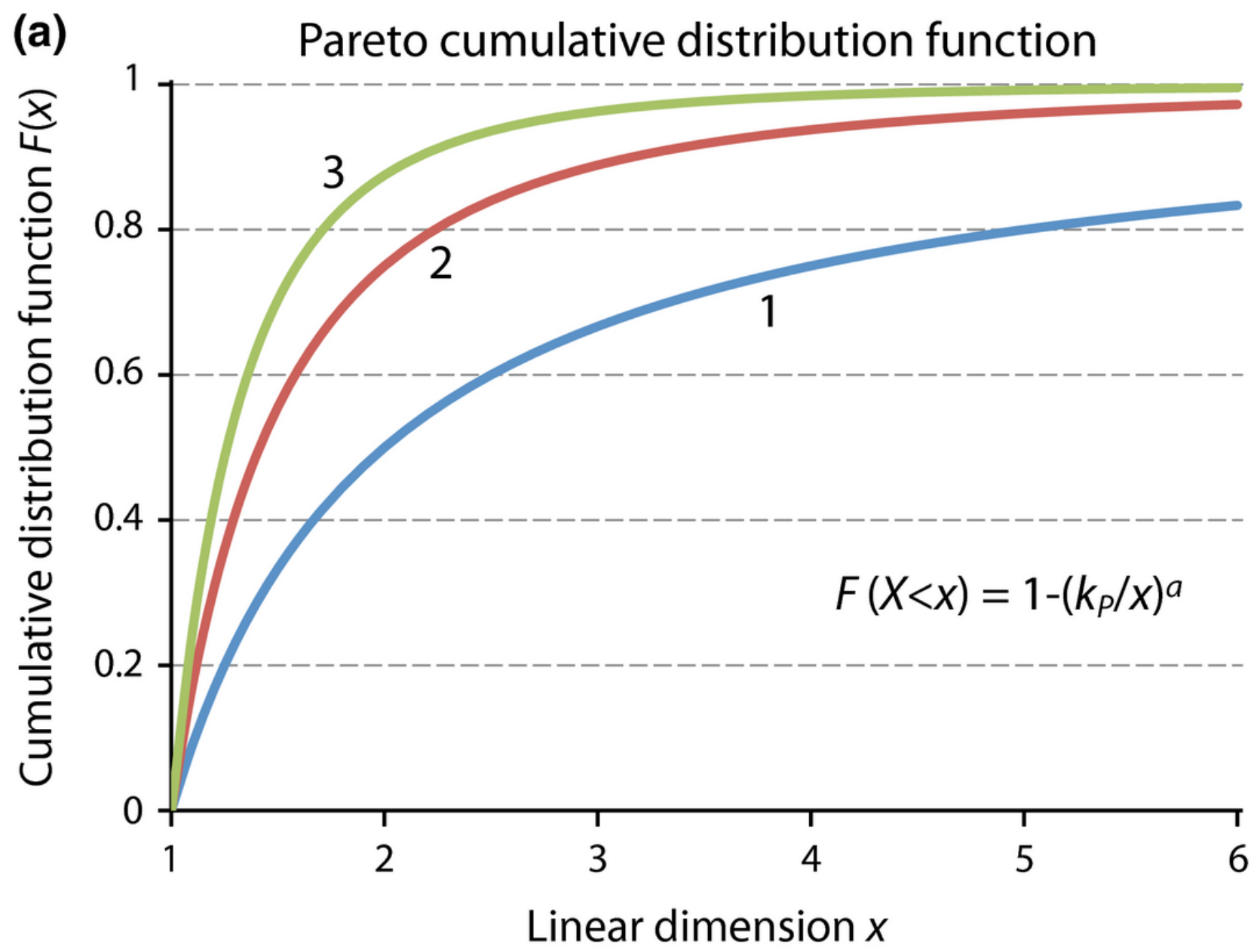

(b)

Pareto probability distribution function

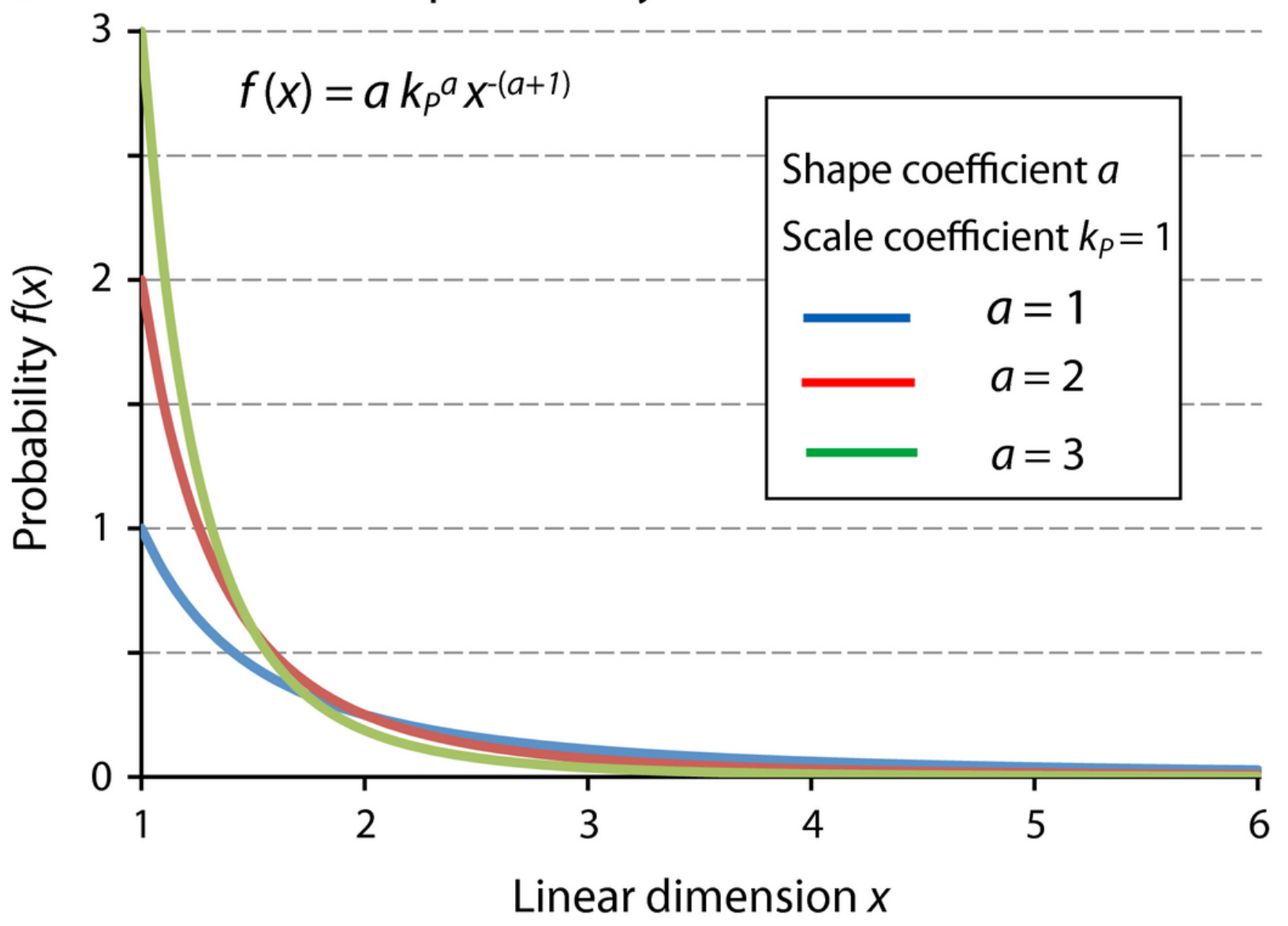




\section{Figure 2.}

Open in figure viewer

Cumulative distribution function $F(x)$ (a) and probability distribution function $f(x)$ (b) for a standard $\left(k_{p}=1\right)$ Pareto distribution for values of the shape parameter $a$ of 1,2 and 3.

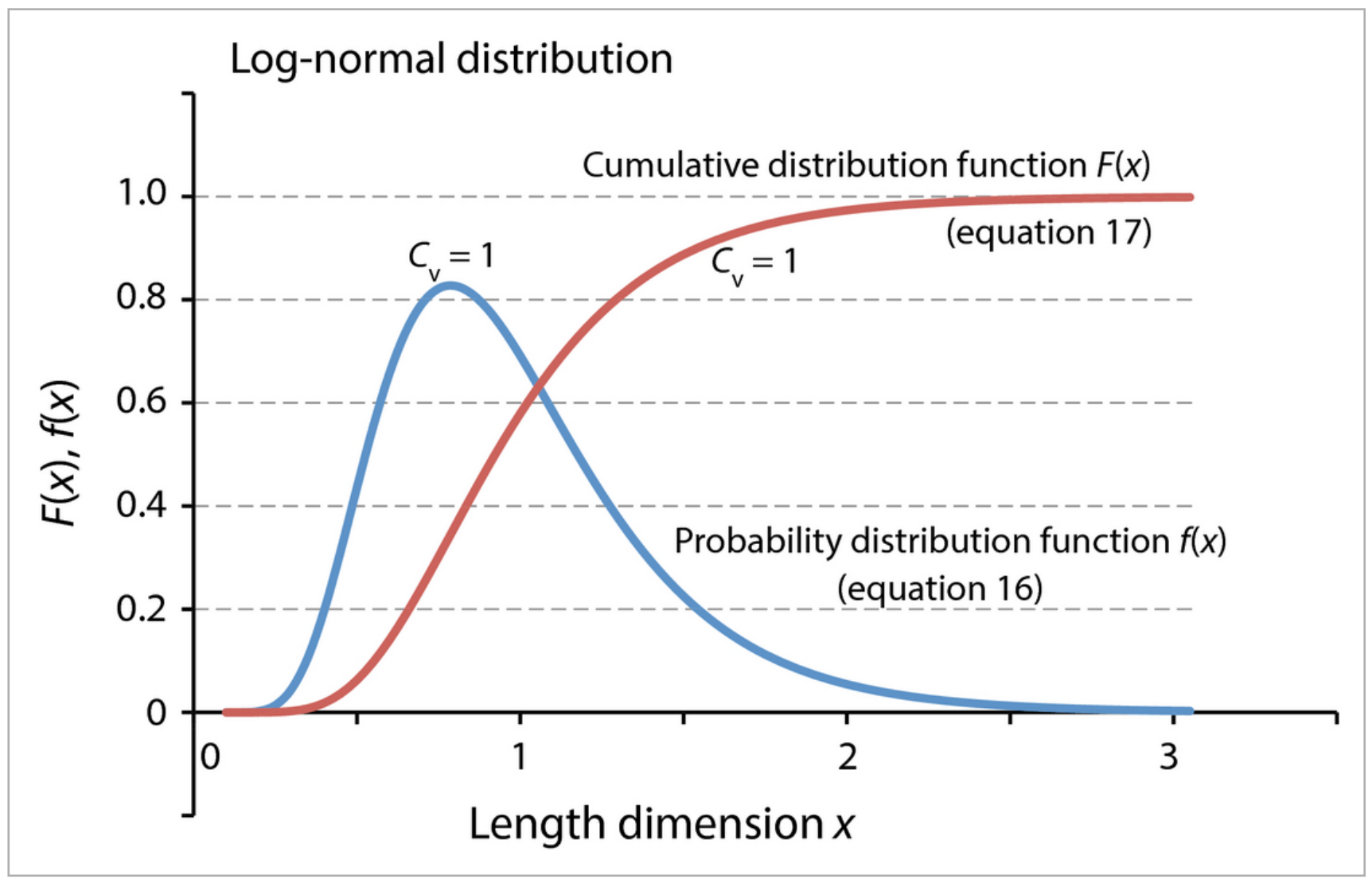

Figure 3.

Open in figure viewer

Cumulative distribution function $F(x)$ and probability distribution function $f(x)$ for a log-normal distribution with a covariance $C_{v}$ of 1 and a unit mean length dimension. 


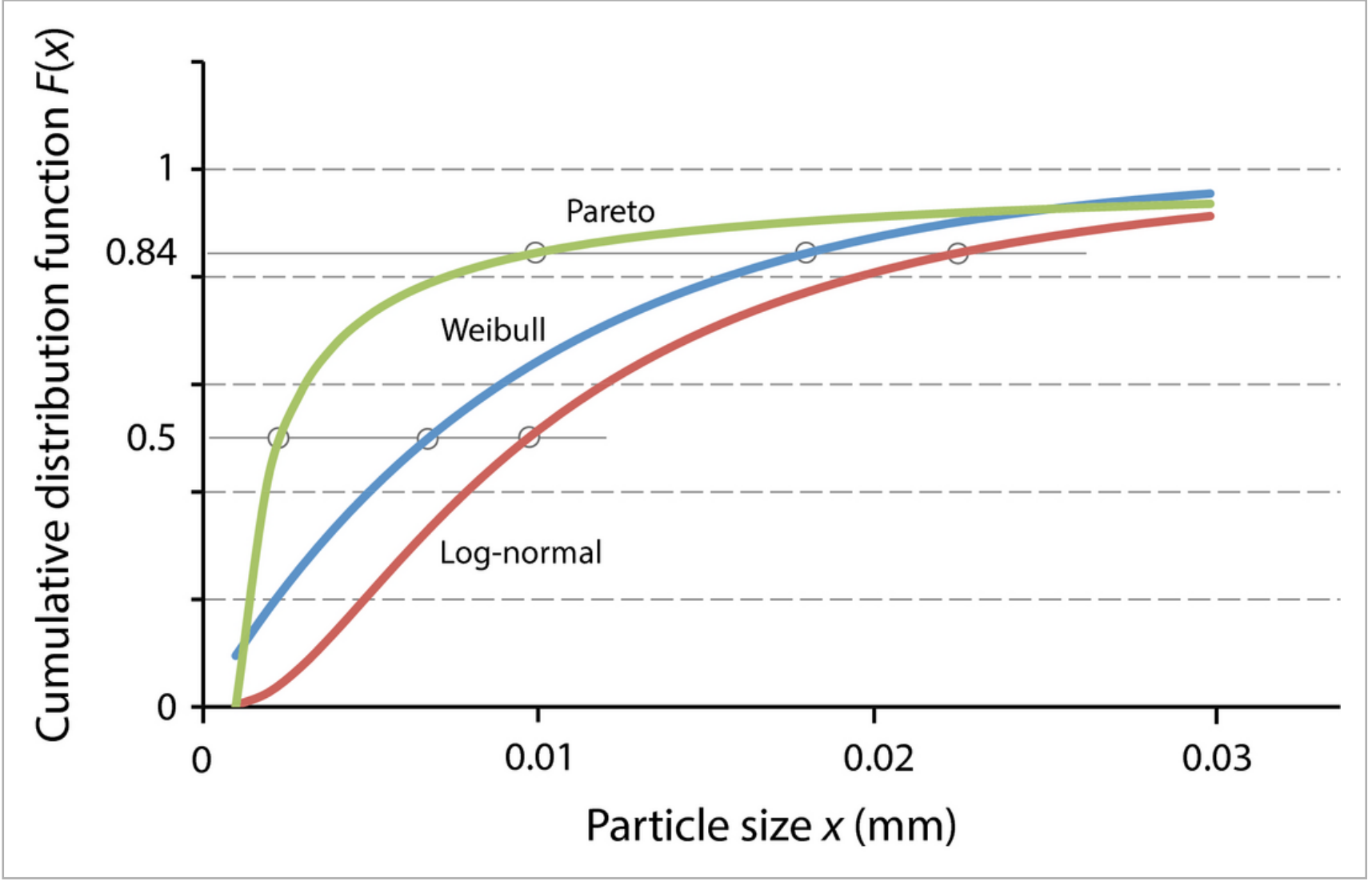

\section{Figure 4.}

\section{Open in figure viewer}

Comparison of the cumulative Pareto distribution with the exponential Weibull distribution and the log-normal distribution for a fine-grained sample. The Weibull distribution is calculated with an average particle size $k w$ of $0.01 \mathrm{~mm}$ and a value of $n$ (reciprocal of spread) of 1 . The lognormal distribution is calculated with the same mean particle size (normal distribution) of $0.01 \mathrm{~mm}$, and standard deviation (normal distribution) of 0.01 , giving a covariance $C_{v}$ of 1 , implying a strongly skewed distribution rich in fine particles. The Pareto distribution is calculated with a scale parameter $k_{p}$ of 0.001 , representing minimum grain size, and a shape parameter a of 0.8 . The 50 th and 84 th percentiles are shown.

In this contribution, we assess the changes taking place in the particle size distribution of regolith as it undergoes increasing mobilization and transport in the sediment cascade from source to sink. Clast size measurement of regolith, the bedload of trunk channels in eroding catchments, debris flow deposits on proximal basin-margin fans and fluvial gravels that have undergone far-field transport, are compared with statistical models, with the view to gaining predictive insights into the fractionation processes of sediment dispersed from erosional source regions.

\section{Methods}

Size distributions have been evaluated using a number of techniques including the measurement at random of the long and short axes of at least 100 clasts following the method adapted from Wolman (1954) (Leopold, 1970; Green, 2003), the use of digital images and by sieving $<300 \mathrm{~kg}$ of sediment in the field.

We compare a number of statistical models with grain size data collected from a range of sediment types, 
(southern Italy and Sicily), proximal debris flow deposits that have suffered little granulometric change during emplacement (Owens Valley, California), and fluvial gravels that have been transported far from source (Eocene of the southern Pyrenees of northern Spain and Miocene-Pliocene of the Great Plains, USA).

The Pareto distribution is closely associated with fractal distributions, and can profitably be used to approximate the self-similar fractal distributions (Sornette, 2006) associated with the fragmentation process of weathering. It has a cumulative distribution function given by

$F(x)=1-\left(\frac{k_{P}}{x}\right)^{a}$

for $x \geq k_{P}$, where $a$ is a power exponent in the Pareto distribution, also known as the shape coefficient, and $k_{P}$ is the minimum value, also known as the scale coefficient. The unknown parameters of the Pareto distribution can be evaluated by interpolation between specified grain size values. Here, interpolation is carried out using values of the 84th and 50th percentiles derived from the cumulative function distribution of grain size based on Wolman-type clast counts. Let the proportion of a sample that has particles below a grain size $D_{b}$ be denoted by $P_{b}$, and let the proportion of a sample that has particles below a grain size $D_{c}$ be denoted by $P_{c}$. In the general case, the estimate of the shape parameter a becomes

$a=\frac{\log \left(1-P_{b}\right)-\log \left(1-P_{c}\right)}{\log \left(D_{c}\right)-\log \left(D_{b}\right)}$

where $a$ is the shape parameter, and the estimate of the scale parameter $k_{P}$ is given by

$k_{P}=\left\{\frac{P_{c}-P_{b}}{\left(1 / D_{b}^{a}\right)-\left(1 / D_{c}^{a}\right)}\right\}^{1 / a}$

Any two grain sizes can therefore be used to solve equations (3) and (2). The 84th and 50th percentiles are

$F(X<0.84)=\left(\frac{25}{4}\right)^{1 / a} k_{P}$

and

$F(X<0.5)=2^{1 / a} k_{P}$

from which a can be solved to give

$a=\frac{\log (25 / 8)}{\log \left(D_{84} / D_{50}\right)}$

The mean of the Pareto distribution is

$\mu=\frac{a k_{P}}{(a-1)}$

which exists only for $a>1$ and the median is given by

$M=2^{1 / a} k_{P}$

The standard deviation is given by

$\sigma=\frac{\sqrt{\frac{a}{(a-2)}} k_{P}}{(a-1)}$ 
The drawback with the application of the Pareto distribution to gravel-grade grain size data is that there is a minimum length scale $k_{p}$ below which the probability $f(x)=0$. Yet the minimum length scale is greater than the size of the smallest grains measured $(1-2 \mathrm{~mm})$. As a result, the Pareto distribution is not a good approximation to the grain size distributions reported here in the region $2<x<k_{P}$ in $\mathrm{mm}$. This has implications for the goodness of fit tests reported below.

Materials that have been subjected to disintegration or fracturing have also been reported to follow an exponential size distribution known as the Rosin law, or Rosin-Rammler law (Krumbein \& Tisdel, 1940; Kittleman, 1964). Fits of empirical data with the Rosin law are typically good up to a certain maximum size, and it has been speculated that Rosin parameters change with transport length in river channels or that the distribution is replaced by a log-normal distribution (Blatt et al., 1980). Others (Ibbeken, 1983) have suggested that gravel grade sediment maintains its Rosin distribution along the entire length of the river whereas the sand fraction behaves log-normally

The Rosin law expresses the cumulative weight or volume fraction less than a given size by $F(X<x)=1-\exp \left(-\left(x / k_{W}\right)^{n}\right)$

which is also known as the Weibull distribution. The coefficient $k_{w}$ is the mean of the grain size, calculated from the full set of clast size data, and $n$ is an integer generally taken as unity. The 50th and 84th percentiles are respectively

$D_{50}=(0.693147)^{1 / n} k_{W}$

and

$D_{84}=(2.995732)^{1 / n} k_{W}$

The mean of the Weibull distribution is a gamma function

$\mu=k_{W} \Gamma\left(1+\frac{1}{n}\right)$

Log-normal distributions involve the transformation of the length dimension so that $x^{*}=\ln (x)$, which ensures that all values of $x^{*}$ are positive. The log-normal distribution has its own mean and standard deviation $\mu^{*}$ and $\sigma^{*}$. If the covariance is defined as the ratio of the standard deviation and mean of the normal distribution, $C_{v}=\sigma / \mu$, the standard deviation and mean of the log-normal distribution are

$\sigma^{*}=\left[\ln \left(1+C_{v}^{2}\right)\right]^{1 / 2}$

and

$\mu^{*}=\ln \left[\frac{\mu}{\left(1+C_{v}^{2}\right)^{1 / 2}}\right]$

The log-normal probability distribution function is given by

$f(x)=\frac{1}{x \sigma^{*}(2 \pi)^{1 / 2}} \exp \left[-\frac{\left(\ln (x)-\mu^{*}\right)^{2}}{2\left(\sigma^{*}\right)^{2}}\right]$

and the cumulative distribution function is given by

$F(x)=1-\frac{1}{2} \operatorname{erfc}\left[\frac{\left(\ln (x)-\mu^{*}\right)}{2^{1 / 2} \sigma^{*}}\right]$

where $x^{*}$ is the mean of the log-normally distributed values, $\sigma^{*}$ is the standard deviation of the lognormally distributed values, and erfc is the complementary error function. When computing values for the 
complementary error function it should be remembered that erf $(-x)=-\operatorname{erf}(x)$ and that erfc $(x)=$ $1-\operatorname{erf}(x)$. The values of $\mu^{*}$ and $\sigma^{*}$ can be calculated from the logarithm of the full set of grain size data.

The closeness of the cumulative distribution functions of the Pareto, Weibull and log-normal models to the observed cumulative function distribution of field data can be assessed visually, but the goodness of fit is better evaluated quantitatively using the Kolmogorov-Smirnov vertical difference parameter $D_{k s}$. This parameter is the greatest deviation of a cumulative distribution function of grain size data from a reference or model cumulative distribution. Consequently, small values of $D_{K S}$ indicate a close fit. The K-S statistic is calculated for the goodness of fit between the observed data and the Pareto, Weibull and log-normal statistical models using samples from the erosional source region and at increasing distances of transport from the depositional apex of the sediment routing system. When assessing the goodness of fit of the Pareto distribution, the K-S statistic is initially calculated for a truncated range of the grain size $\left(x>k_{P}\right)$ since $k_{P}$ is the minimum value. Secondly, the Pareto distribution is further truncated to give a narrower range of $F(x)>F\left(x_{P}\right)$, where $x$ is the observed grain size and $x_{P}$ is the grain size from the Pareto model. Executing this base truncation of the Pareto distribution commonly means that the goodness of fit is carried out only to grain sizes above the median $D_{50}$. This is clearly a less exacting test than those carried out on the Weibull and log-normal distributions but is necessary to account for the distorting effect of $F(x) \rightarrow 0$ as $x \rightarrow k_{P}$ (see Discussion).

\section{Results}

\section{Holocene debris flow deposits, eastern California}

An initial example is taken from young sediment deposits, located a small distance from the catchment serving as a sediment source area, which illustrates the comparison of clast measurement data with a statistical model. The material comprising these proximal debris flows is most likely close to the starting grain size distribution fluxed out of upland catchments and delivered to sedimentary basins. Counting of the sizes of over 2000 clasts from the central channels and lateral levees of Holocene debris flows on the proximal part of Shepherd Creek fan, Owens Valley, eastern California (Fig. 5), reveals a cumulative distribution for channels and levees that can be compared with statistical models (Fig. 6). Debris flow deposits in Owens Valley have been dated using cosmogenic nuclides (Dühnforth et al., 2007; Le et al., 2007; D'Arcy et al., 2015), which provides an age of $6.2 \pm 3.0 \mathrm{ka}$ for the Holocene surface on Shepherd Creek fan, based on 8 individual ${ }^{10} \mathrm{Be}$ boulder samples. Boulders are granitic in composition, derived from Cretaceous plutonic rocks in the catchment in the Sierra Nevada (Moore, 1981). 


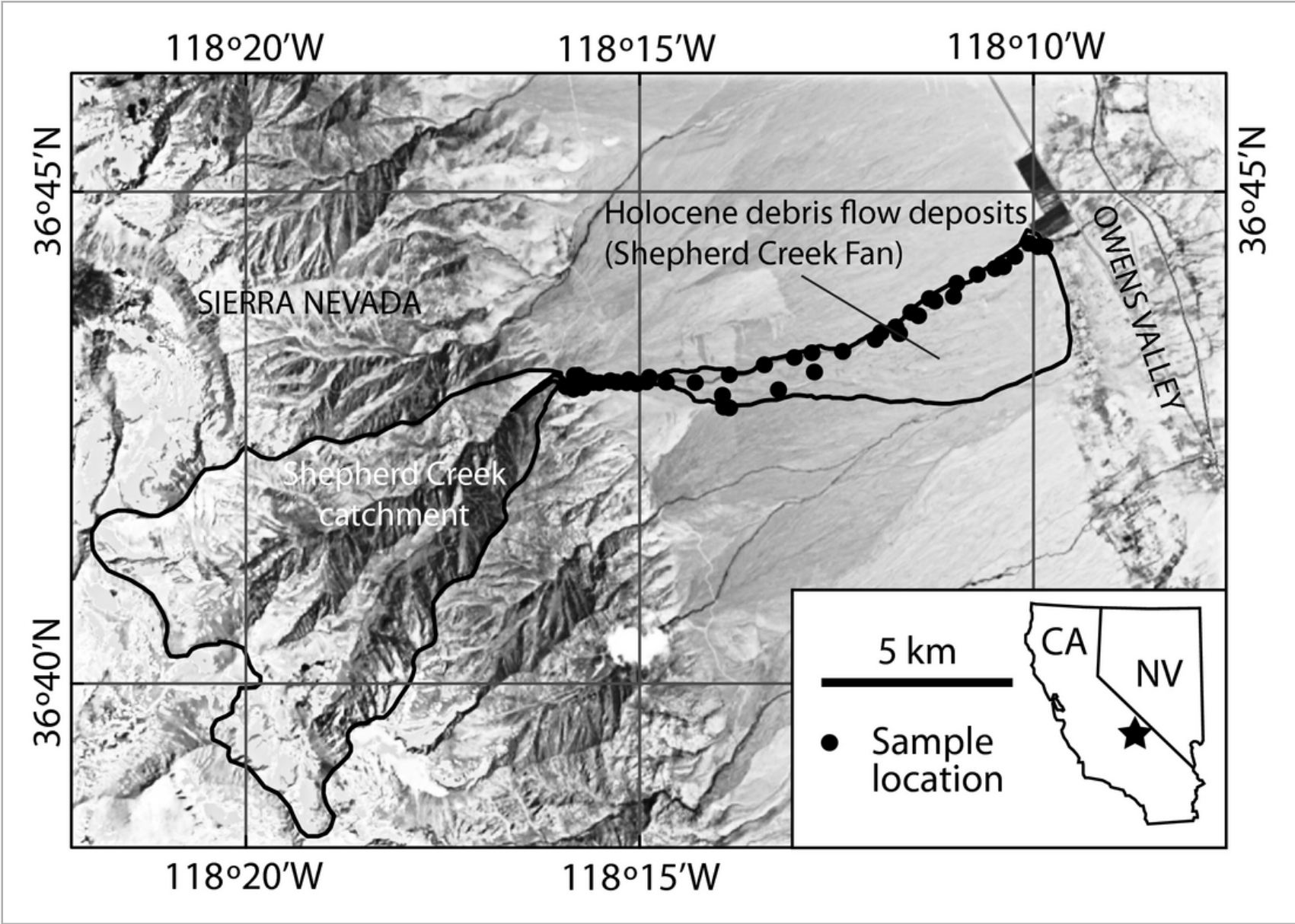

\section{Figure 5.}

Open in figure viewer

Locality map of Shepherd Creek catchment and fan, western Owens Valley, California, showing sample locations for clast size analysis.
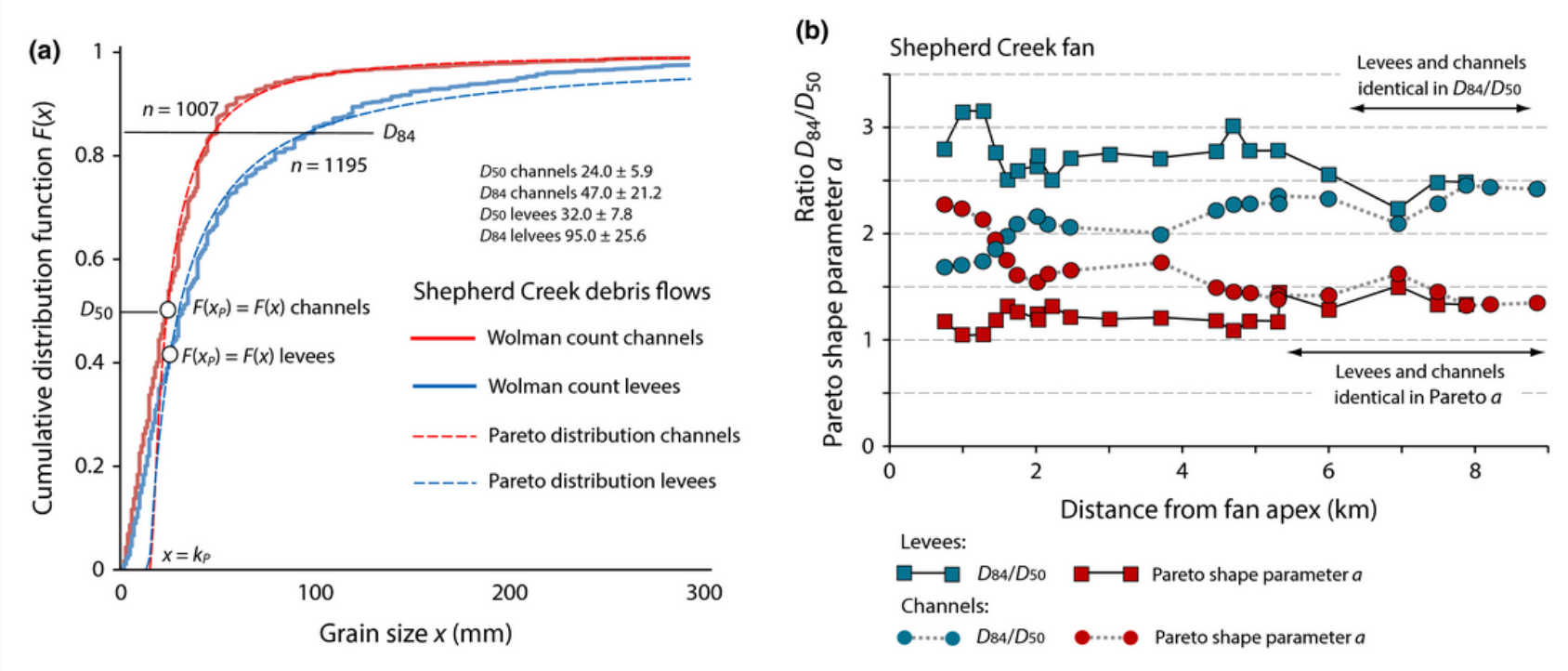

Figure 6.

Open in figure viewer 
(a) Cumulative distribution function $F(x)$ for clast size data collected using the Wolman method from the proximal part of Shepherd Creek fan, Owens Valley. Cumulative curves are for central channel deposits and lateral levee deposits, which are compared with Pareto distributions using $D_{84}$ and $D_{50}$ derived from statistical analysis of the field data. The cumulative curves were generated by Pareto interpolation as explained in the main text. (b) Down-system profiles of clast size parameters from debris flow deposits on Shepherd Creek fan, Owens Valley.

Measurements of clasts in central channels of debris flow deposits $(n=1008)$ give a mean size $\mu$ of $36.0 \mathrm{~mm}$ and standard deviation $\sigma$ of $55.5 \mathrm{~mm}$, with a value of 1.56 for the ratio $\sigma / \mu$ (Table 1). The 50 th (median) and 84th percentiles are 24.5 and $47.0 \mathrm{~mm}$, giving a ratio $D_{84} / D_{50}$ of 1.92 . Clasts in the lateral levees of debris-flow deposits are coarser, with a mean of $58.7 \mathrm{~mm}(n=1196)$. The standard deviation is $101.0 \mathrm{~mm}$, which gives a value of $1.72 \mathrm{for} \sigma / \mu$. The 50th (median) and 84th percentiles are 32.0 and $95.0 \mathrm{~mm}$, giving a ratio $D_{84} / D_{50}$ of 2.97 .

Table 1. Grain size characteristics of the central channels and lateral levees of Holocene debris flow deposits on Shepherd Creek fan, Owens Valley, eastern California

\begin{tabular}{|c|c|c|}
\hline Parameter & Channels $(n=1008)$ & Levees $(n=1196)$ \\
\hline Sample mean $\mu(\mathrm{mm})$ & 36.0 & 58.7 \\
\hline Sample variance $\sigma^{2}(\mathrm{~mm})$ & 3083 & 10195 \\
\hline Sample standard deviation $\sigma(\mathrm{mm})$ & 55.5 & 101.0 \\
\hline$\sigma / \mu$ & 1.56 & 1.72 \\
\hline 84th percentile $D_{84}(\mathrm{~mm})$ & 47.0 & 95.0 \\
\hline 50th percentile $D_{50}(\mathrm{~mm})$ & 24.5 & 32.0 \\
\hline$D_{84} / D_{50}$ & 1.92 & 2.97 \\
\hline Pareto shape parameter a & 1.75 & 1.05 \\
\hline Pareto scale parameter $(\mathrm{mm}) k_{P}$ & 16.5 & 16.5 \\
\hline \multicolumn{3}{|l|}{ Kolmogorov-Smirnov statistic $D \mathrm{KS}$} \\
\hline Pareto model (truncated) & 0.064 & 0.040 \\
\hline Weibull model & 0.119 & 0.114 \\
\hline Log-normal model & 0.067 & 0.032 \\
\hline
\end{tabular}

The Pareto cumulative distribution function can be calculated from these field data (equations (2) or 6), giving a shape parameter $a$ of 1.75 and 1.05 for the channels and levees respectively. The mean clast size from field data can be compared with the Pareto values derived from equation (7). This gives a close match for the central channels (36 mm from field data, $38.5 \mathrm{~mm}$ from equation (7)) as a >>1, but the value of the mean has no meaning for the debris flow levees, since $a$ is very close to 1 . This illustrates the limitations of the Pareto model at low values of the shape parameter $a$. The cumulative distribution function from equation (1) shows an excellent fit with the field data derived from clast measurement except 
at very small values of the length scale $x$ (Fig. 6a). The cumulative distribution function shows that there is a relatively greater contribution from large clasts in the lateral levees, which is reflected in the higher mean value, higher $\sigma / \mu$, higher variance and lower shape parameter a (Table 1 ).

The results outlined above demonstrate grain size segregation during emplacement of the debris flow deposit. Johnson et al . (2012) combined data from large-scale debris flow experiments with modelling to show the particle pathways during mass flow emplacement, which demonstrated that coarser clasts are advected to the front of the mass flow and then into lateral levees. The contrast of particle size distributions from levees and channels reported here are a striking confirmation of this process.

There is no systematic down-fan variation in $D_{84} / D_{50}$, suggesting that this dimensionless group can be used as a similarity variable (Fedele \& Paola, 2007; Duller et al., 2010) (Fig. 6b). Values of the ratio $D_{84} / D_{50}$ are different for levees and channels in the proximal fan, but converge to approximately 2.5 farther down-system at distances $>7 \mathrm{~km}$ from the catchment outlet. Although the Pareto scale parameter $k_{P}$, representing minimum grain size, is identical between central channels and lateral levees, the corresponding Pareto shape parameter a differs significantly in the proximal part of the fan. As with $D_{84} / D_{50}$, the Pareto shape parameter a converges for both levees and channels at a value of about 1.3 in the distal fan.

A goodness of fit test using the Kolmogorov-Smirnov statistic allows the Pareto model to be compared with the Weibull and log-normal models (Fig. 7). The greatest variability of fit is at grain sizes $<100 \mathrm{~mm}$. Below this clast size, the log-normal and truncated Pareto distributions give the closest fit. Despite their large differences in clast size and Pareto shape parameter, debris flow levees and channels have similar goodness of fit statistics (Table 1), suggesting that the identical source region characteristics and emplacement mechanism of the debris flows has left a strong statistical fingerprint in the deposits of the proximal region of Shepherd Creek fan. 


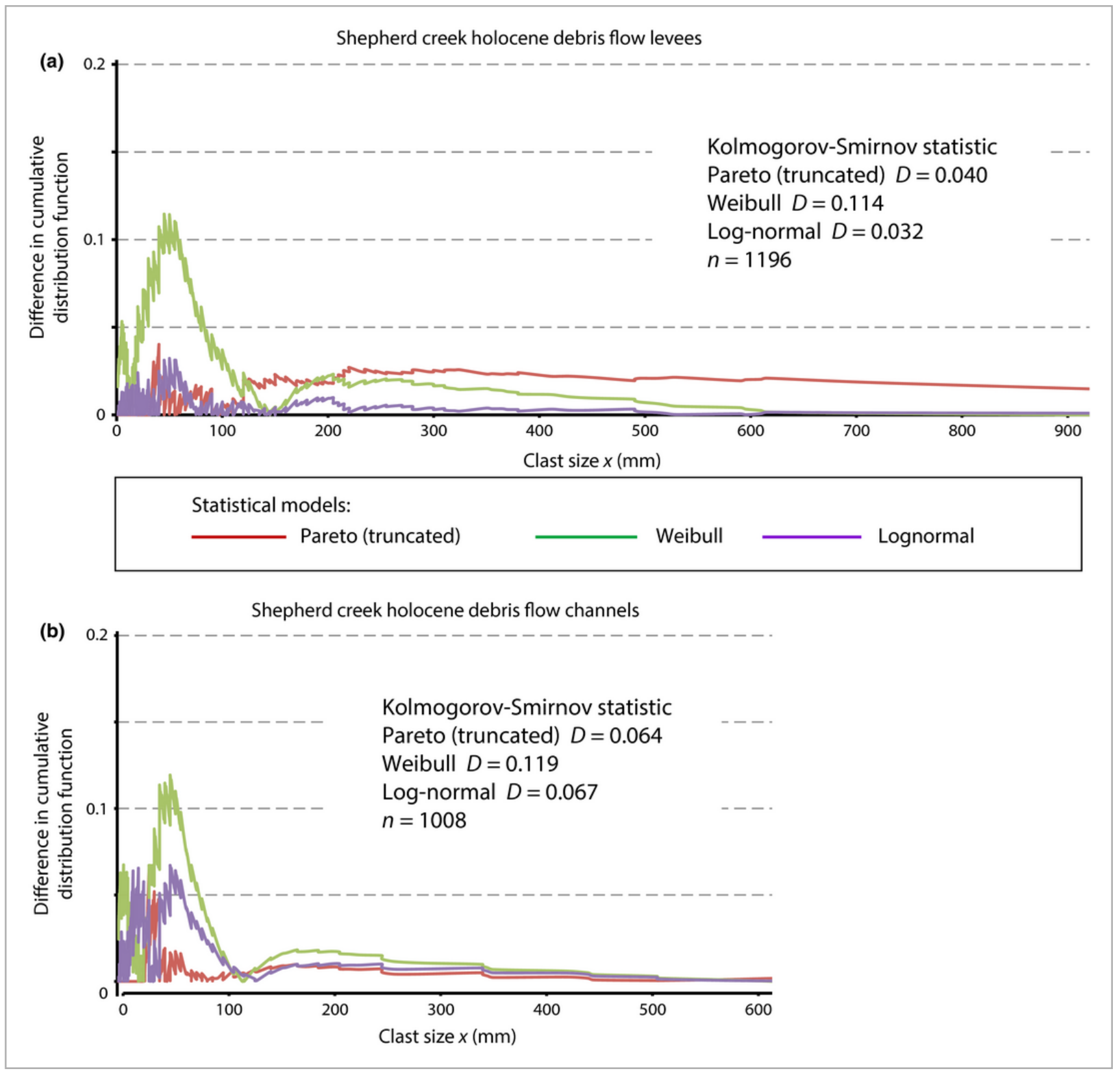

Figure 7.

Open in figure viewer

Comparison of statistical models in terms of their goodness of fit using the Kolmogorov-Smirnov statistic $D_{K S}$ for levees (a) and channels (b) of Holocene debris flows in the proximal region ( $<3 \mathrm{~km}$ from fan head) of Shepherd Creek fan, eastern Owens Valley, California.

On extending the investigation to fan surfaces of different age in the Owens Valley region (Table S1), levees and channels are well differentiated. Both levees and channels have Pareto a values that are historically higher than modern values, suggesting that over time the fan surface is infiltrated by fine particles. Debris flow channels are fitted well by a log-normal distribution but levees are equally well fitted by log-normal and truncated Pareto statistical models (Fig. 8). 


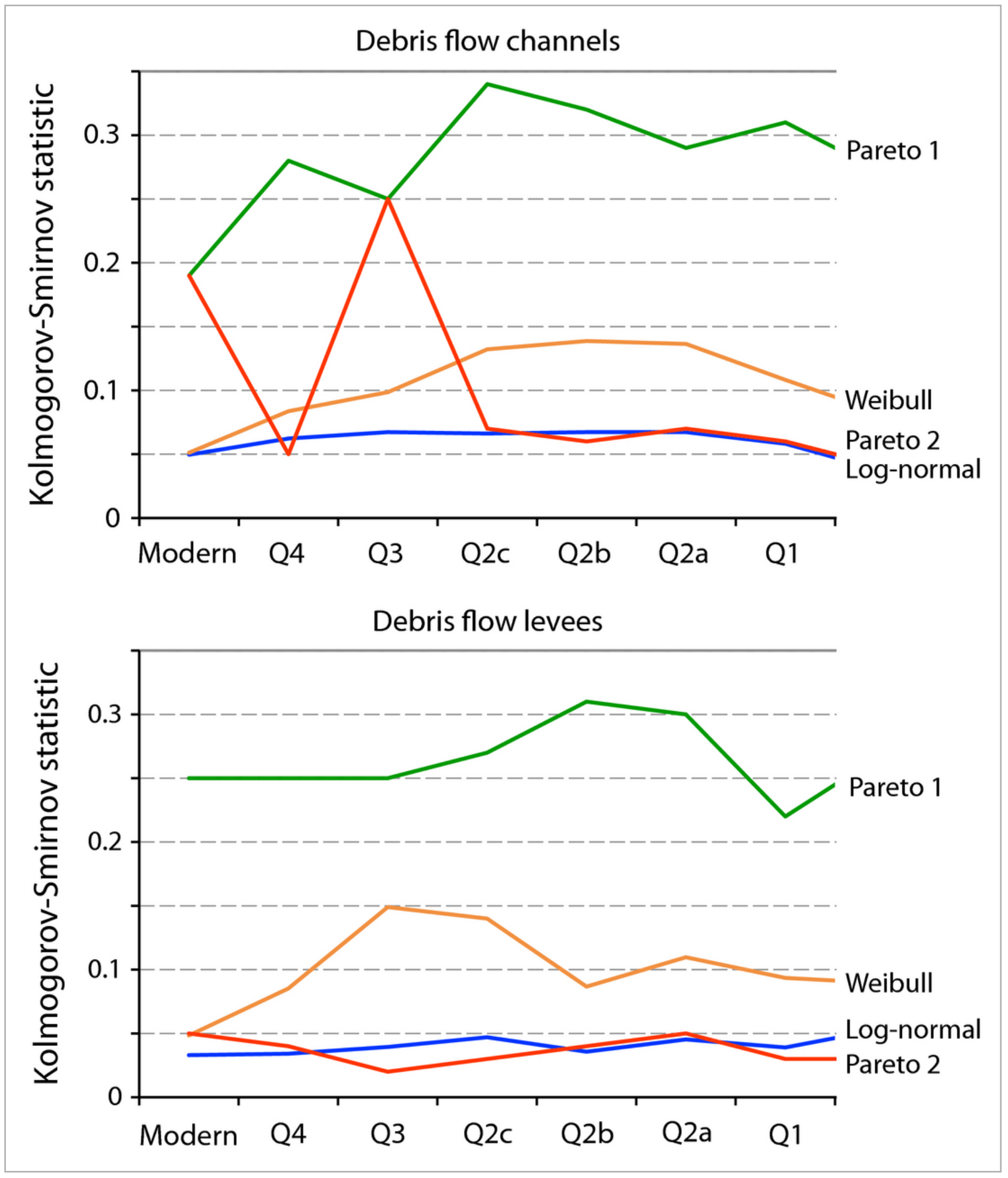

\section{Figure 8.}

\section{Open in figure viewer}

Comparison of statistical models in terms of their goodness of fit using the Kolmogorov-Smirnov statistic $D_{k S}$ for channels and levees of debris flow deposits of different age in the Owens Valley region, California. Pareto 1 is a truncated Pareto model for $x>k_{p}$. Pareto 2 is further truncated to only include values of $x$ where the cumulative distribution function of the Pareto model exceeds the cumulative distribution function of the field data, $F\left(x_{P}\right)>F(x)$. These truncations reduce or remove the effect of the Pareto probability $\rightarrow 0$ as $x \rightarrow k_{p}$. Stratigraphic subdivisions of the Quaternary are from D'Arcy et al . (2015). 


\section{Regolith, channel bedload and catchment outlet sediment, Italy}

A second example is taken from the weathering products formed on a range of bedrock lithologies in tectonically uplifting catchments in southern Italy (Table S2) (Fig. 9). Samples were also taken from sediment at the outlets of the transverse catchments where they cross the range-bounding fault (Table S4). The cumulative distribution functions for regolith vary considerably according to bedrock lithology (Fig. 10).

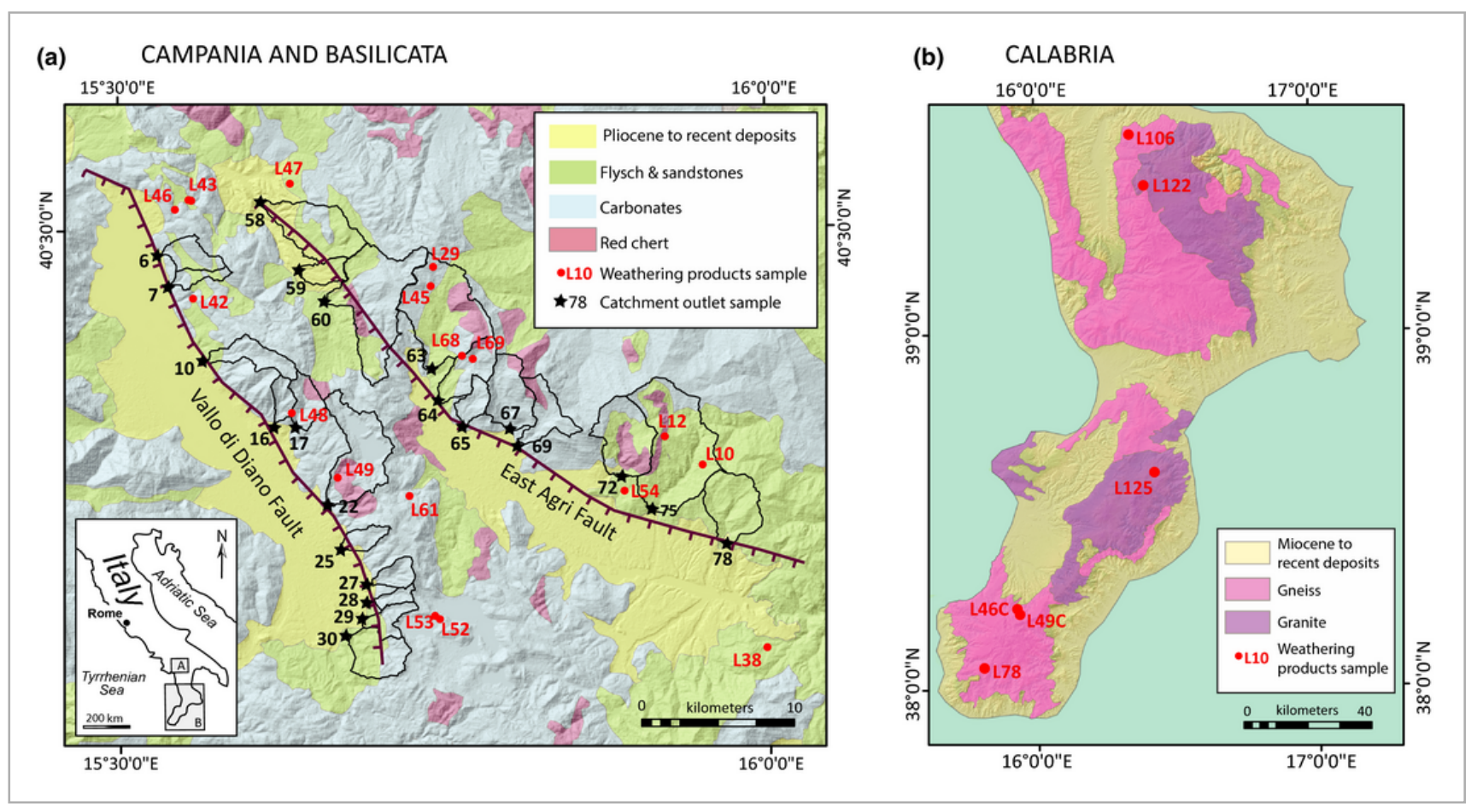

\section{Figure 9.}

Open in figure viewer

Simplified lithological maps of the Campania and Basilicata (a) and Calabria (b) field areas, southern Italy, overlying a hillshade DEM image. Localities of field sampling of weathering products are shown in red, and sampling sites of sediments at the outlets of footwall catchments in (a) are marked with a black star. Modified from Figure 6 in Allen et al . (2015).

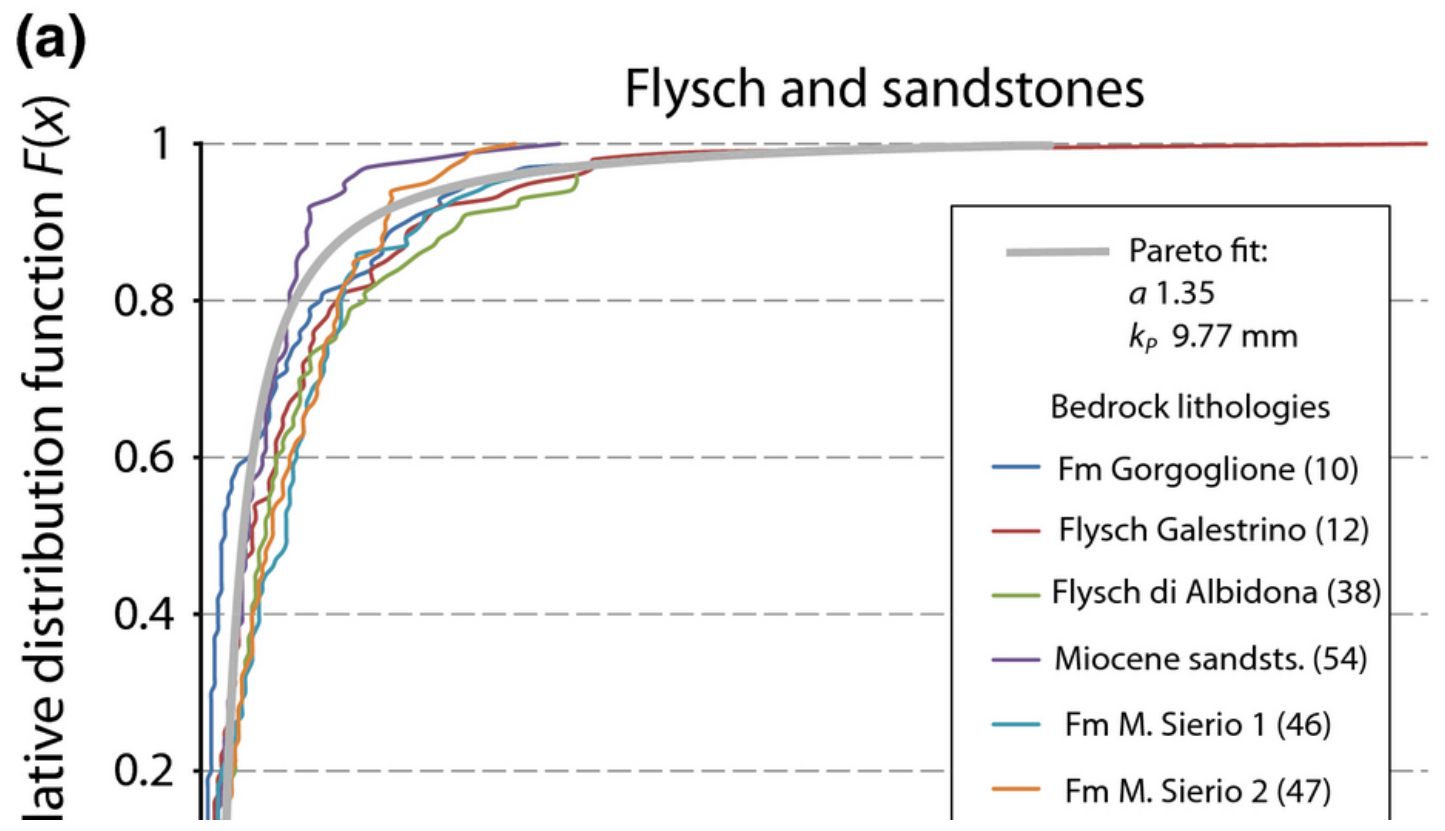


100

200

300

Grain size (mm)

(b)

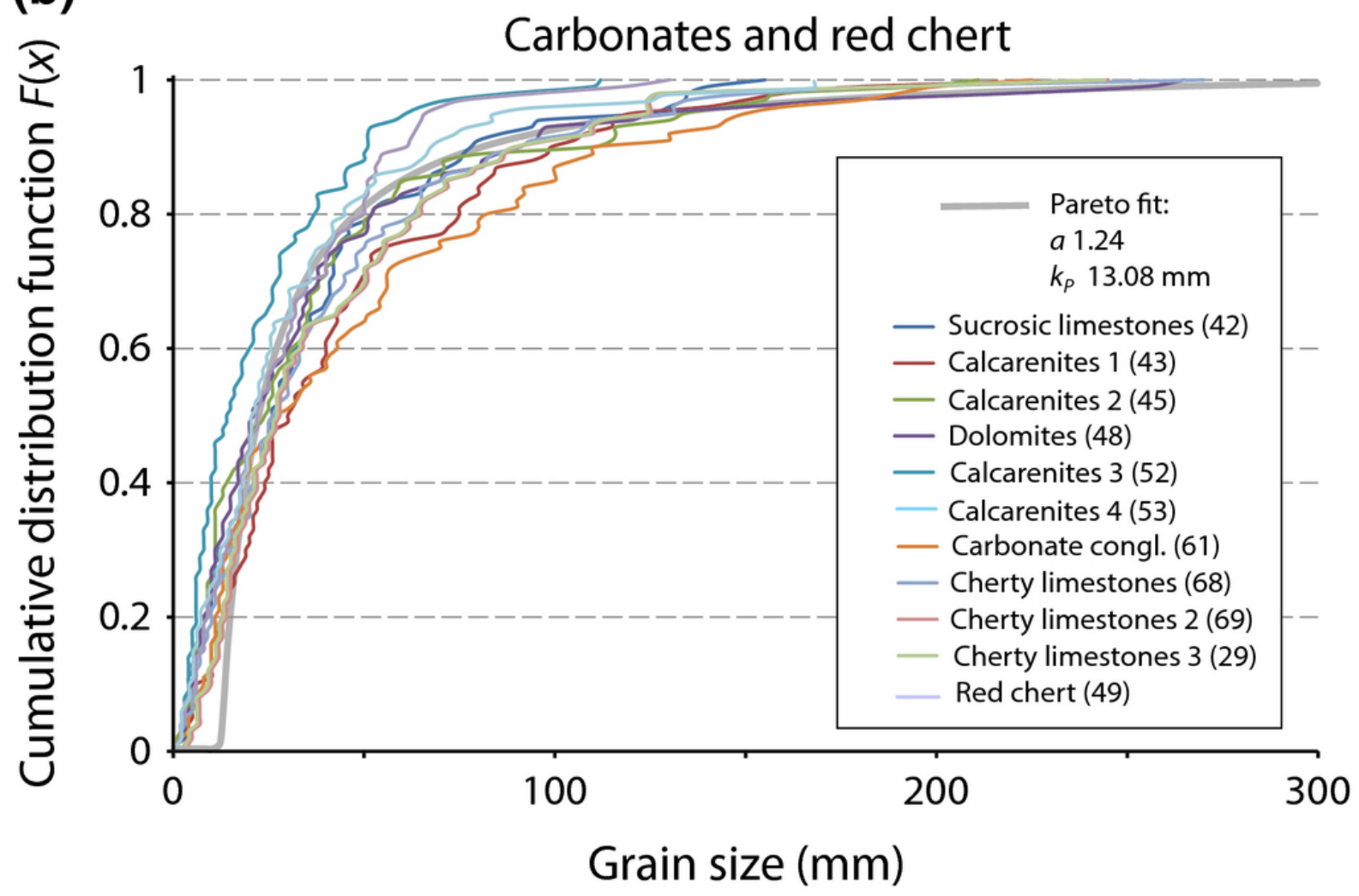

(c)

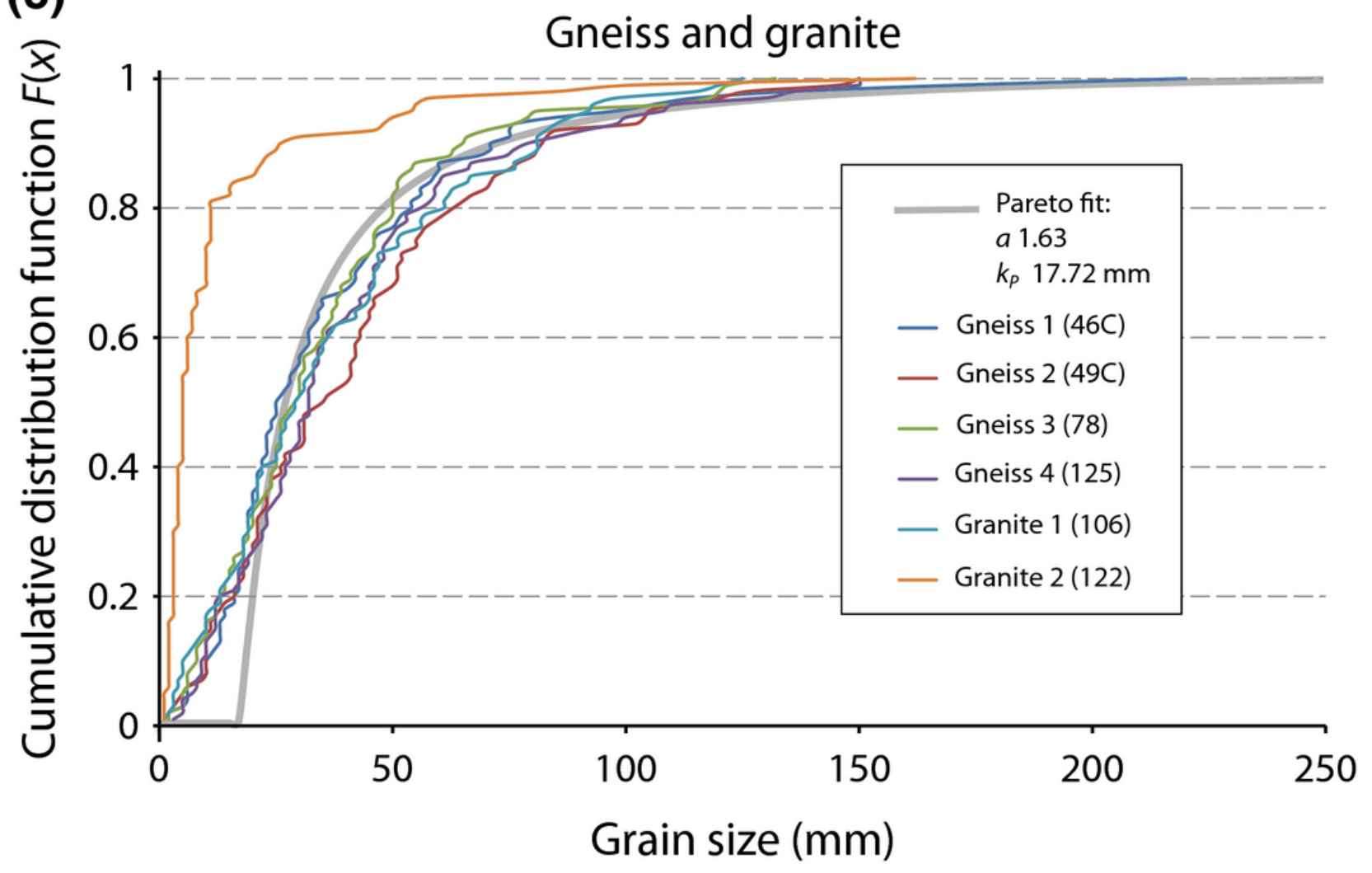




\section{Figure 10.}

\section{Open in figure viewer}

Analysis of weathering products in Campania, Basilicata and Calabria, Italy, using the Wolman clast counting method. Basilicata and Campania have regoliths developed on Flysch sandstones and mudstones, carbonates and red chert, whereas the Calabrian catchments are underlain by granite and gneiss. The average values of $D_{84}$ and $D_{50}$ were calculated for each lithological class and used to interpolate the shape parameter $a$ and the scale parameter $k_{P}$ for the Pareto cumulative distribution function (thick grey line). Locality IDs are found in Fig. 9 and in Table S2.

The average Pareto shape parameter for regolith developed on gneissic/granitic bedrock in Calabria is 1.63 , but decreases to an average of $a=1.28$ for catchments on flysch (mudstones-sandstones) and carbonates in Basilicata and Campania. The gneiss and granite bedrock is evidently weathering to produce regolith with a relatively high contribution of smaller clasts compared to the bedrock lithologies in Basilicata-Campania.

A goodness of fit analysis shows the Pareto, Weibull and log-normal models to all provide a good fit $\left(D_{K S}<0.1\right.$ ) with the cumulative distribution functions of regolith developed on carbonate bedrock (Fig. 11). The fits on flysch (mudstones and sandstones) and granites/gneisses are more variable; the Weibull Kolmogorov-Smirnov statistic is significantly higher for carbonate bedrock than those for flysch and granites/gneisses (Fig. 11). For the range of bedrock lithologies sampled, the truncated Pareto and log-normal models provide equally good fits for the coarser half of the gravel-grade particle size distribution and the full gravel-grade particle size distribution respectively. 


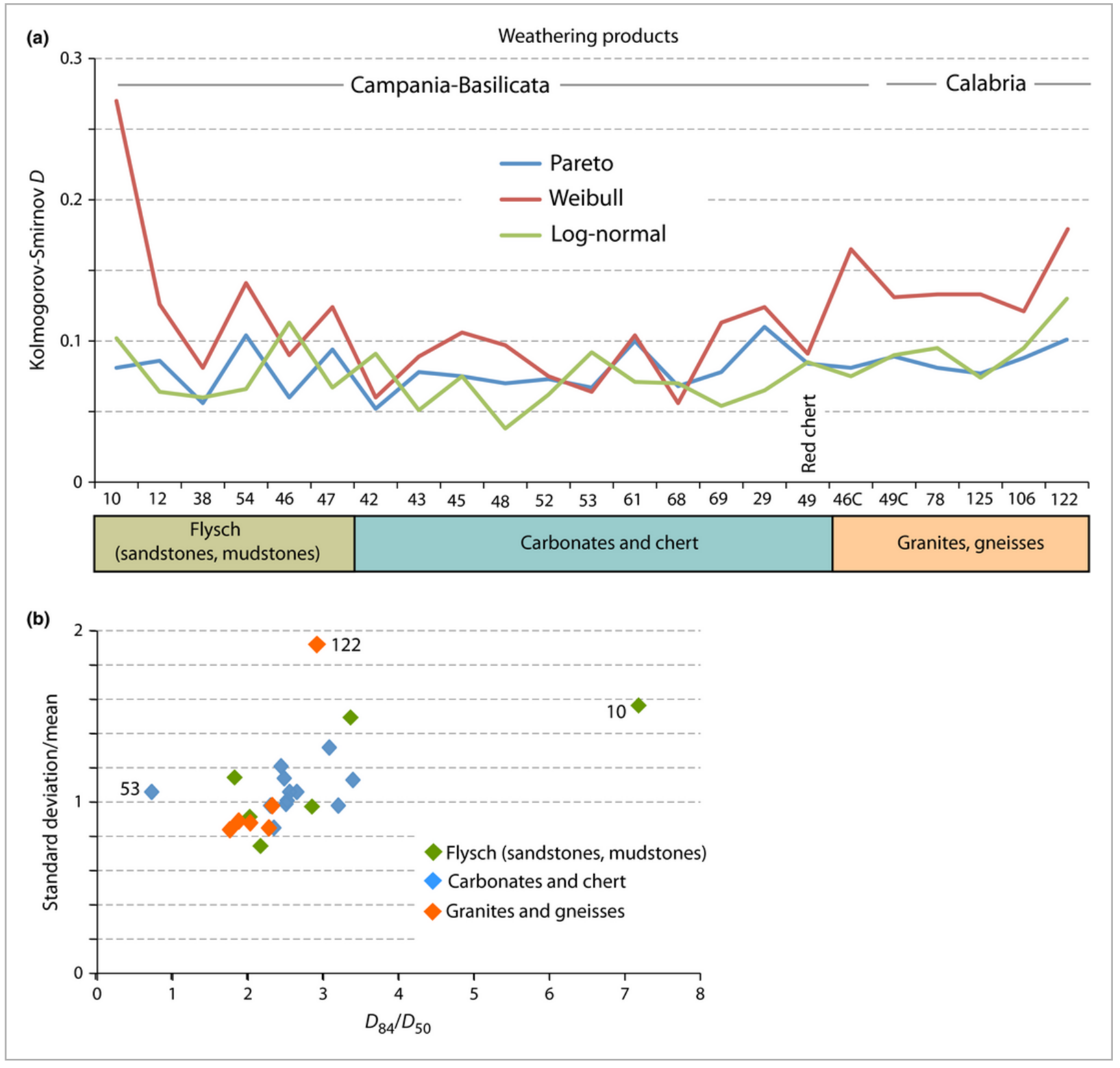

\section{Figure 11.}

\section{Open in figure viewer}

(a) Kolmogorov-Smirnov goodness of fit statistic for weathering products in southern Italian catchments compared to the Pareto, Weibull and log-normal statistical models. Locality IDs are found in Fig. 9 and in Table S2. (b) Plot of $\sigma / \mu$ vs. $D_{84} / D_{50}$ for weathering products from catchments with bedrock geology dominated by Flysch, carbonates and gneisses/granites. Three outliers are labelled with their locality ID.

The cumulative distribution functions for bedload sediment at the outlets of 22 catchments in Campania and Basilicata, southern Italy, are shown in Fig. 12, together with the Pareto model calculated by interpolation from the 50th and 84th percentiles. The average shape parameter for sediment at catchment outlets along the Vallo di Diano ( $n=11)$ and East Agri ( $n=11)$ faults in Campania and Basilicata is very similar (Table S4), with averages of 1.32 and 1.23 respectively. This is expected, as the weathering products of flysch and carbonate bedrocks have very similar Pareto statistics. Interestingly, sediment at the outlet points of catchments and regolith in the same catchments are indecipherable in terms of the average Pareto shape parameter (data in Tables S2 and S4), suggesting little change to the grain size 
distribution as sediment is mobilized from regolith and transported the short distance to the catchment outlet.
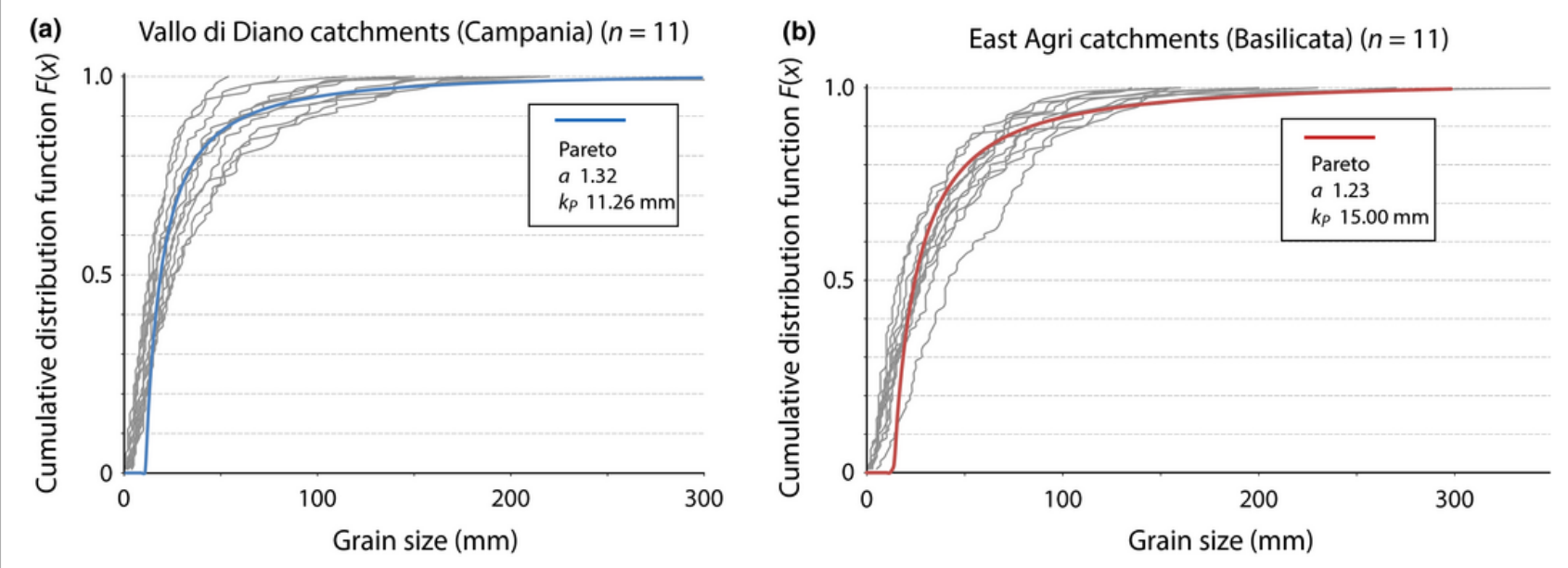

\section{Figure 12.}

\section{Open in figure viewer}

Compilation of cumulative distribution functions for the grain size of sediment at the outlets of catchments along the Vallo di Diano (Campania) and East Agri (Basilicata) faults, based on the Wolman clast counting method, together with Pareto cumulative distributions based on the average values of $D_{84}$ and $D_{50}$.

A goodness of fit analysis (Table S5) shows a variable fit of the Pareto, Weibull and log-normal models along the strike of the Vallo di Diano and East Agri Faults (Fig. 13). As with regolith, the Weibull model provides the least good fit with field data.

\section{Figure 13.}

\section{Open in figure viewer}

(a) Kolmogorov-Smirnov goodness of fit statistic for bedload sediment at catchment outlets along the Vallo di Diano and East Agri Faults, southern Italy, compared to the Pareto, Weibull and lognormal statistical models. Locality IDs are found in Fig. 9a and in Tables S4 and S5. (b) Plot of $\sigma /$ $\mu$ vs. $D_{84} / D_{50}$ for sediment at catchment outlets along these two linked fault systems.

The Pareto shape parameter for the bedload material in three Sicilian catchments (Pagliara, Fiumedinisi and Agro) (Fig. 14) is calculated by interpolation using $D_{84}$ and $D_{50}$ for a number of stations at different distances from the outlet. The average value of a varies from 1.53 for the large Fiumedinisi catchment ( $n=22$ ), to 1.06 for the intermediate-sized Pagliara catchment ( $n=16$ ), and 0.65 for the small Agro catchment $(n=9)$ (Table S6). There is no recognizable downstream trend in each catchment, but values of $a$ are systematically higher in the larger catchments (Fig. 15). The range of values of a from bedload $(0.65-1.53)$ is significantly wider than that for regolith and sediment at catchment outlets. However, with the exception of the Agro channel, where $D_{84} / D_{50}$ values are exceptionally high, the data sets from the erosional source area fall within the range 1.06-1.63, with an average of about 1.40 . 


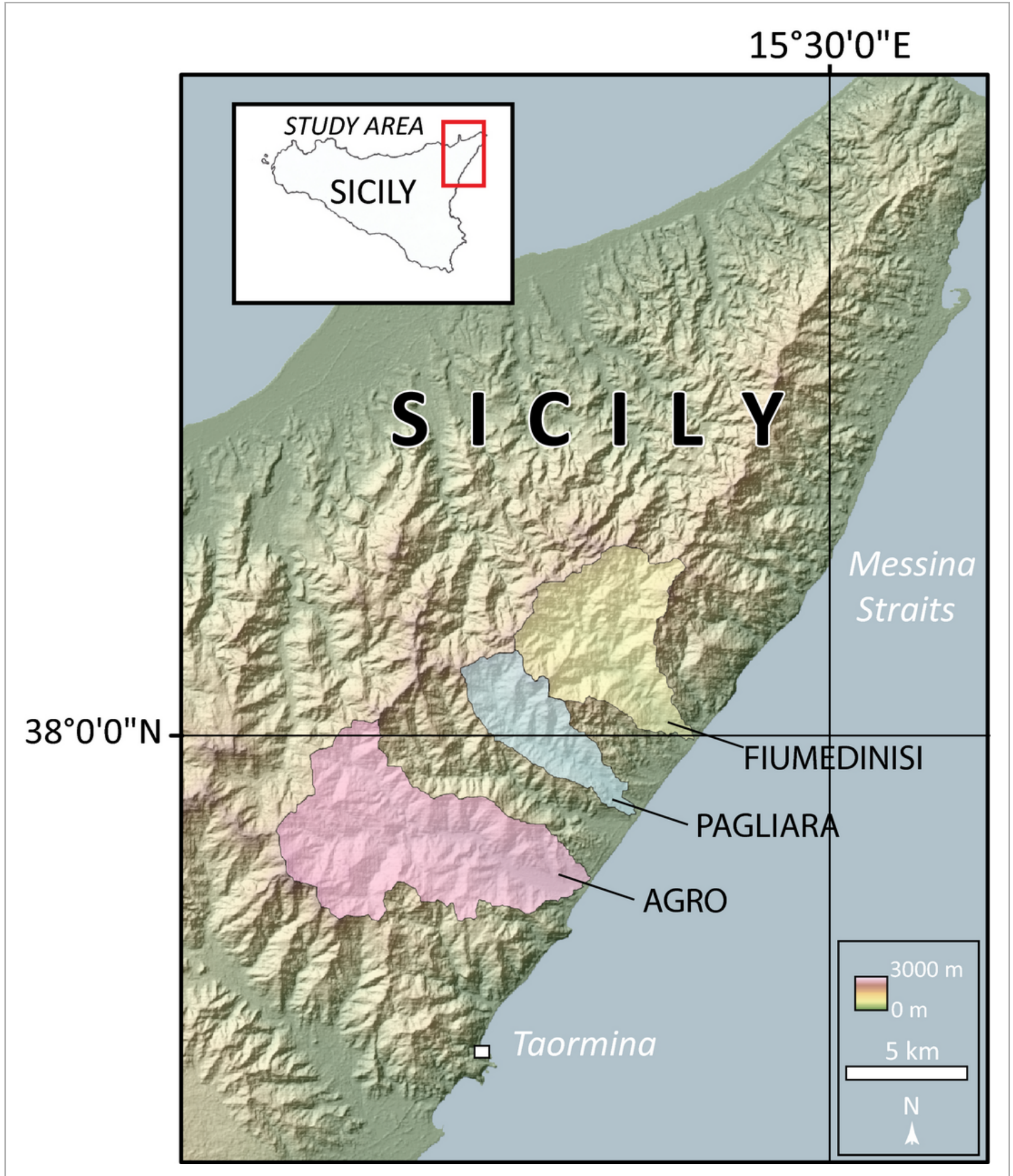

Figure 14.

Open in figure viewer

Hillshaded DEM image showing catchments sampled for bedload material in the main trunk streams in northeastern Sicily. 


\section{Sicilian main catchment channels}

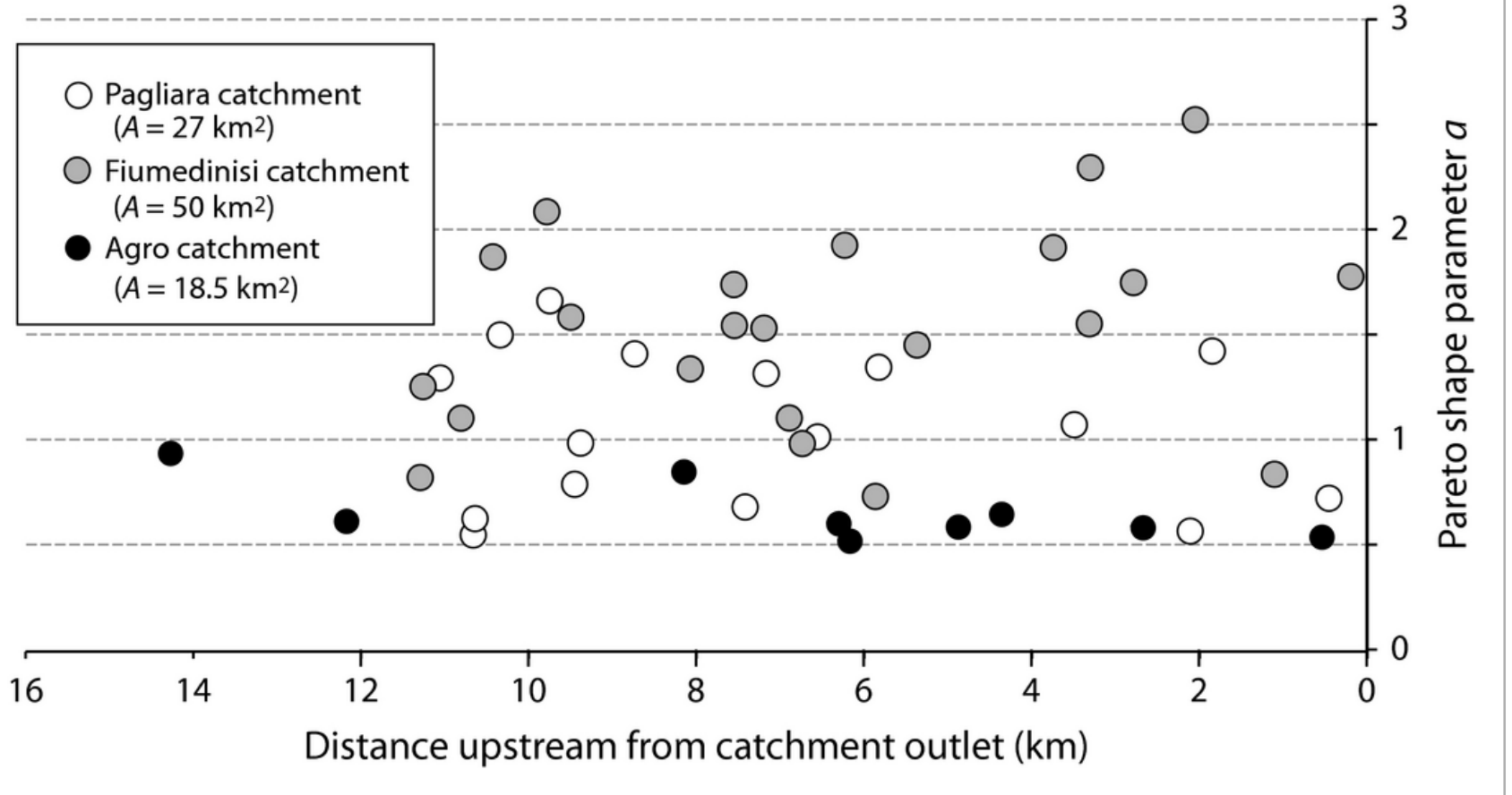

Figure 15.

Open in figure viewer

Plot of Pareto shape parameter a vs. distance upstream from catchment outlet in the trunk channels of the Pagliara, Fiumedinisi and Agro catchments, Sicily. There is no downstream trend, but sets of values are displaced according to catchment area.

The particle size statistics of materials comprising regolith, catchment channel bedload and proximal debris flows are constrained by the information given above. The question naturally arises of whether there is down-system fractionation of grain sizes at larger distances of transport. To answer this question, it is necessary to investigate the granulometry of fluvial gravels dispersed large distances from their source areas. We do this by analysing the Eocene and basal Oligocene of the southern Pyrenean fold-thrust belt, northern Spain and the Miocene-Pliocene gravels of the Great Plains, USA.

\section{Eocene Escanilla and Oligocene Antist palaeo-sediment routing systems, northern Spain}

Gravel-rich deposits are commonly well preserved in the proximal segments of sediment routing systems (Allen \& Heller, 2012), extending from the depositional apex to the gravel front. What is not currently known is how representative the gravel-rich sediments are of the sediment routing system as a whole in terms of grain size statistics and to what extent the statistical properties of river-transported gravels change with increasing distance, or distance normalized by the fractional sediment extraction [the mass balance $x$ coordinate of Paola \& Martin (2012)], from their source. The Eocene and basal Oligocene sedimentary rocks of the Escanilla and Antist palaeo-sediment routing systems respectively, preserved in the foreland of the Pyrenean orogen in northern Spain, allow these questions to be addressed. The Escanilla system was fed with sediment from two main catchments stretching back into the high Pyrenees in the mid to late Eocene (Fig. 16a). The outlet points of these catchments can be identified accurately from the location of thick fluvial conglomerates in the Gurb and Sis areas (Mellere, 1993; Vincent, 2001). The two tributaries met at a confluence in the Tremp Basin, and the unified river system flowed westwards, along the strike of the orogen, to the Ainsa Basin. The palaeo-coastline was initially located in the Ainsa 
Basin (Dreyer et al., 1999) but migrated westwards into the Jaca Basin during the late Eocene. The conglomeratic Antist Group lies stratigraphically above the Escanilla via an angular unconformity. It represents a sheet of gravel that was spread approximately transversely from the decaying topography of the Pyrenean palaeo-orogen towards the foreland basin depocentre in the south (Coney et al., 1996). Michael et al . (2013) and Michael et al . (2014) divided the Escanilla palaeo-sediment routing system into three time intervals, each approximately 2.5 Myr in duration (Table 2), using sedimentological trends and the presence of distinctive marker beds such as conglomeratic sheets and lacustrine limestones (Fig. 16b). By tracing the Escanilla system from catchment outlets to depositional sinks, they were able to investigate how grain size fractions (gravel, sand and finer than sand) changed down-system.

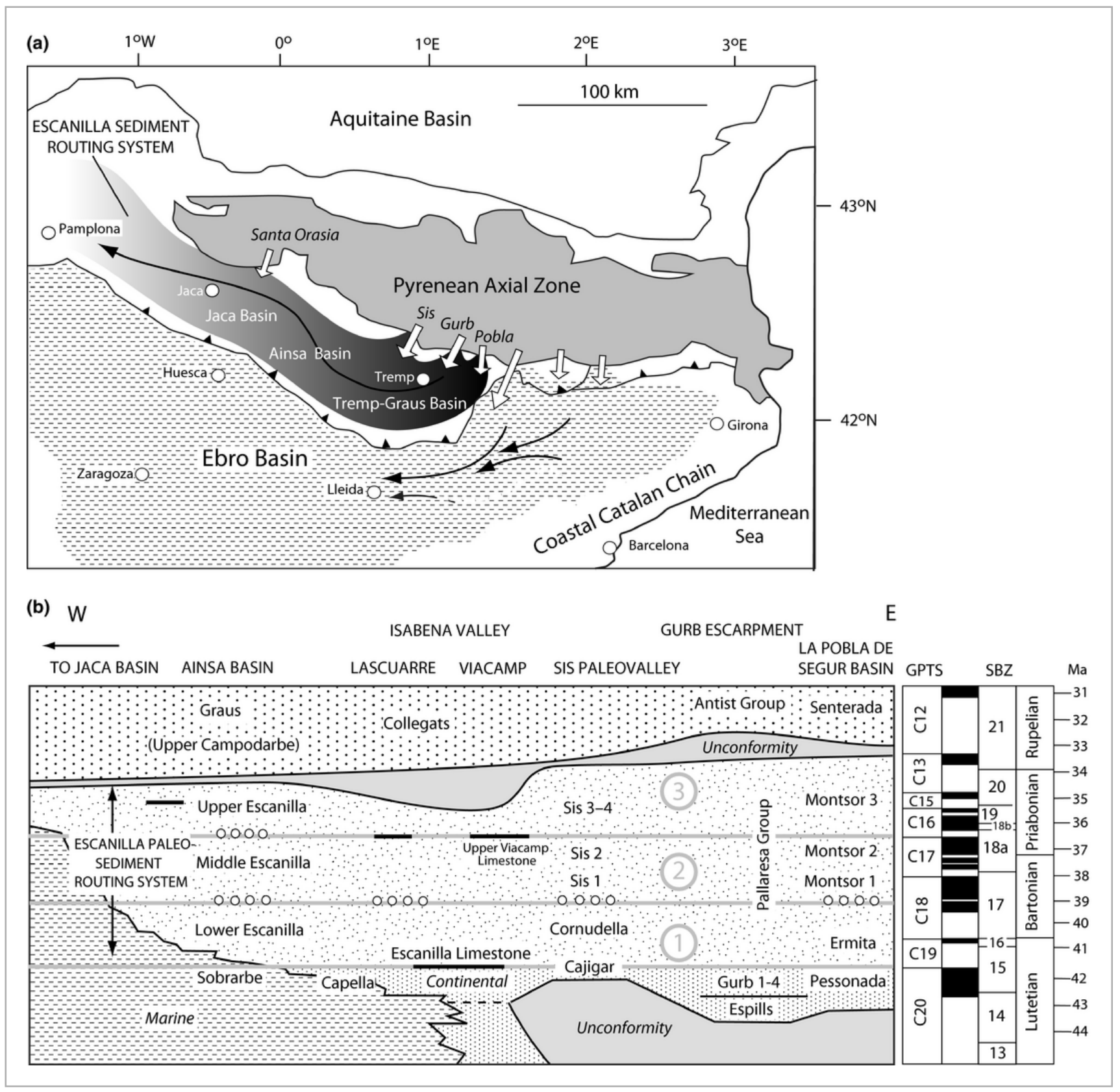

\section{Figure 16.}

\section{Open in figure viewer}

(a) Sediment routing systems in the south Pyrenean region and its foreland basin system in the mid to late Eocene. The Escanilla sediment routing system was situated in a wedge-top position, confined by fold-thrust structures, and dispersed sediment westwards. Modified from Fig. 2 in Michael et al . (2014). (b) Chronostratigraphic summary of the mid-Eocene to Oligocene of the 
south-central tectonic unit of the Pyrenean wedge-top region. GPTZ, global palaeo-magnetic time scale; SBZ, larger foraminifera shallow benthic zone. Modified from Fig. 4 in Michael et al. (2014).

Table 2. Grain size fractions of the three stratigraphic units of the Escanilla palaeo-sediment routing system (Michael et al., 2013, 2014). The Pareto shape parameter a is calculated from equation (2) where $P_{b}$ and $P_{c}$ are the proportions of fines and fines plus sand respectively

\begin{tabular}{|l|c|c|c|c|}
\hline Stratigraphic unit & Gravel fraction (\%) & Sand fraction (\%) & Fines fraction (\%) & Estimated Pareto a \\
\hline Interval 1 & 0.08 & 0.23 & 0.69 & 1.16 \\
Interval 2 & 0.05 & 0.22 & 0.73 & 1.45 \\
Interval 3 & 0.13 & 0.27 & 0.60 & 0.97 \\
Total Escanilla & 0.09 & 0.24 & 0.67 & 1.12 \\
\hline
\end{tabular}

There are several strategies for analysing the grain size characteristics of the Escanilla and Antist palaeosediment routing systems. The first is to assess the properties of the sediment routing system as a whole by calculating a full sediment budget. Second, the geometric ratio $D_{84} / D_{50}$ can be used from clast measurements made in the gravel-rich zone of the systems. Third, individual clast count measurements can be used to generate cumulative function distributions for comparison with Pareto, Weibull and lognormal models as a function of distance from the depositional apex.

The grain size distribution of sediment released from catchments can be estimated by accounting for the sum total of sediment deposited in the sediment routing system. Although a number of examples exist where a sediment budget has been calculated for the entire sediment routing system (Covault et al., 2007, 2011; Romans et al., 2009; Carvajal \& Steel, 2012; Michael et al., 2013, 2014), it is very rare for the budget to include an inventory of grain size fractions. Michael et al . (2013) and Michael et al . (2014), however, assessed the grain size fractionation in three intervals of the Eocene Escanilla palaeo-sediment routing system (Fig. 17). They found that the summation of grain size fractions measured at stations in a down-system direction, from the depositional apex to the depositional limit, gave a bulk grain size mix of $9 \%$ gravel, $24 \%$ sand and $67 \%$ fines (mud and silt) for the 7.7 Myr time period of deposition (Table 2). This bulk grain size mix implies a very significant loading of the grain size distribution with fine particles 


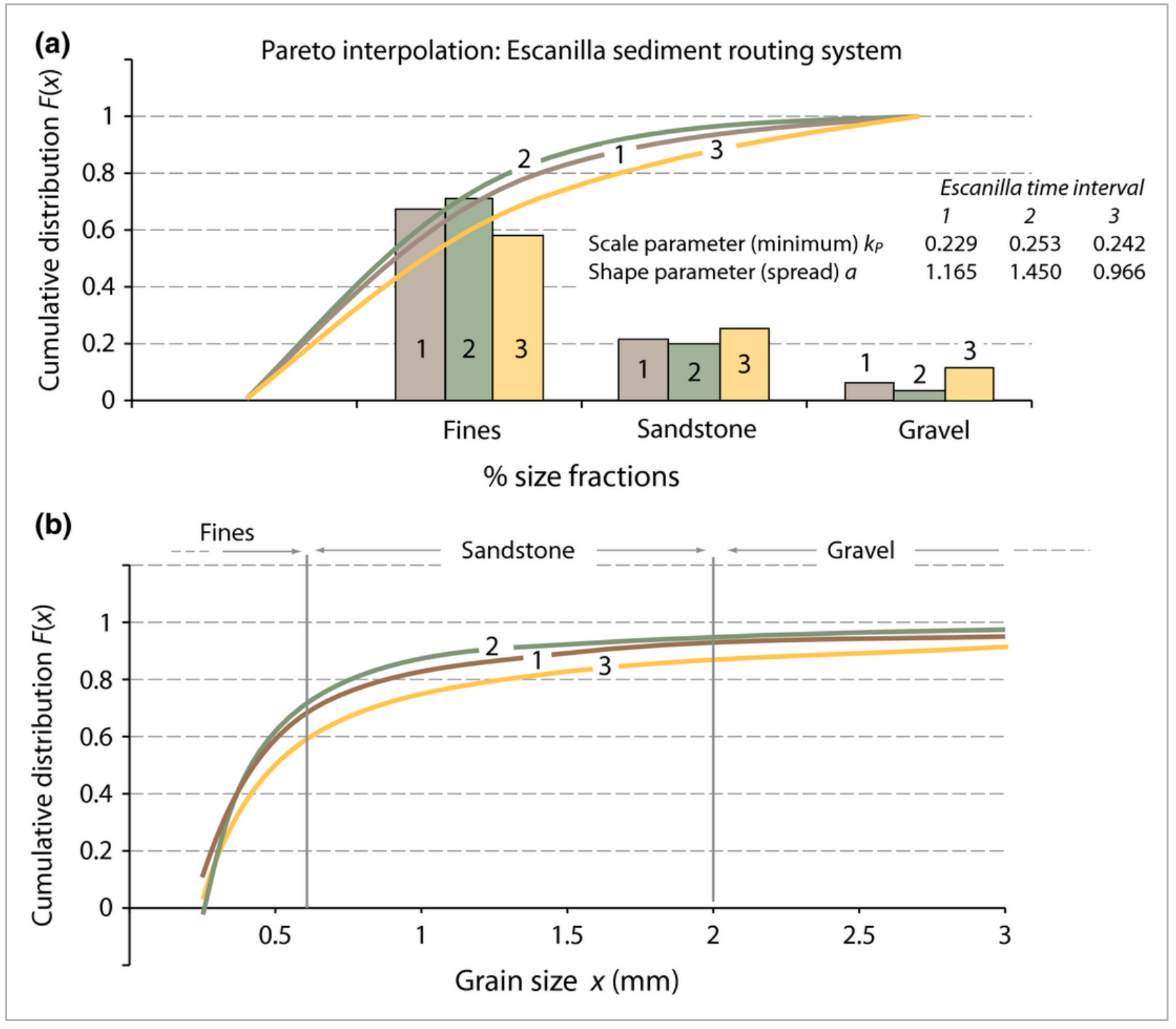

\section{Figure 17.}

\section{Open in figure viewer}

Pareto chart for Time Intervals 1, 2 and 3 of the Escanilla palaeo-sediment routing system. (a) Values of the Pareto shape parameter $a$ and the scale parameter $k_{p}$ are estimated from the grain size fractions of gravel, sandstone and fines in Table 2, using equations (2) and (3). (b) Cumulative distribution function of grain size in mm using the parameter values found in (a).

In equation (2), $b$ and $c$ are set at $2 \mathrm{~mm}$ and $0.625 \mathrm{~mm}$, representing the boundaries between sand and gravel, and silt and sand respectively. The proportions with grain size $<2 \mathrm{~mm}$ and $<0.625 \mathrm{~mm}\left(P_{b}\right.$ and $P_{c}$ ) are the grain size fraction abundances given in Table 2. Carrying out the interpolation yields values of $a$ in the range $0.97-1.45$ for the three time intervals (Fig. 17). The average value of $a$ for the entire palaeo-sediment routing system is 1.12 .

Within the gravel realm of the Escanilla system, the geometric ratio $D_{84} / D_{50}$ is invariant downsystem over a distance of $80 \mathrm{~km}$ from the depositional apex to the gravel front (Figs 18 and 19), suggesting that it can be used as a similarity parameter. The average $D_{84} / D_{50}$ ratio ranges between 2.26 and 2.54 for the 3 time intervals analysed, with an average of 2.36. Likewise, there is no statistically significant down-system variation of the ratio $\sigma / \mu$, with an average value of $0.8-0.9$ (Fig. 19). 

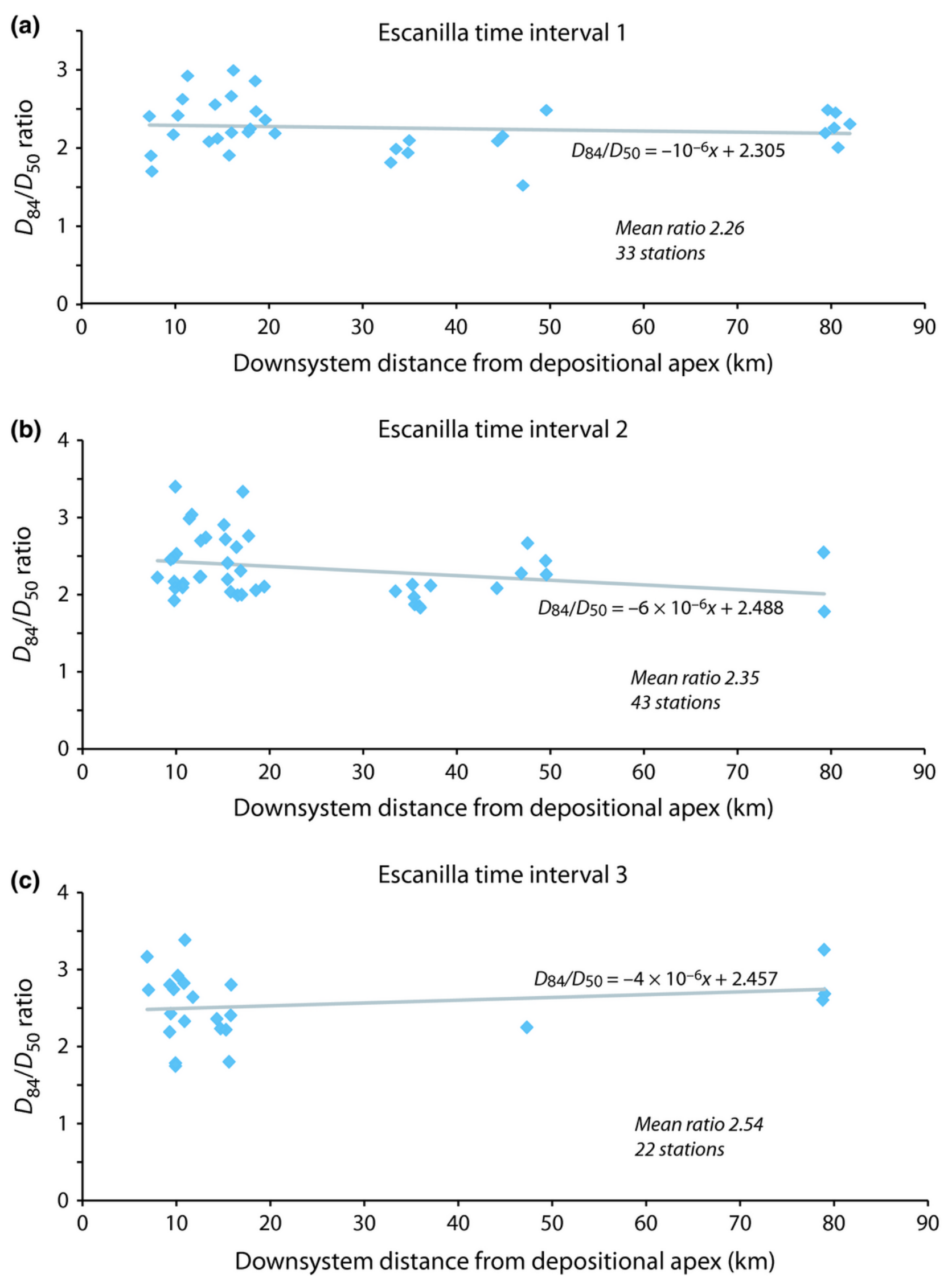

Figure 18.

Open in figure viewer

Grain size trends in three units comprising the Escanilla palaeo-sediment routing system, each of duration ca. 2.5 Myr. $D_{84} / D_{50}$ ratio for time intervals 1 (a), 2 (b) and 3 (c), based on clast 
measurement, after Michael (2013). There is no down-system trend in the grain size ratio $D_{84} / D_{50}$ as seen by the negligible slope of the straight line regressions. The mean value of the $D_{84} / D_{50}$ ratio increases from time interval 1 (oldest) to time interval 3 (youngest), coincident with an increase in the gravel volume in the sediment supply (Michael et al., 2013, 2014).

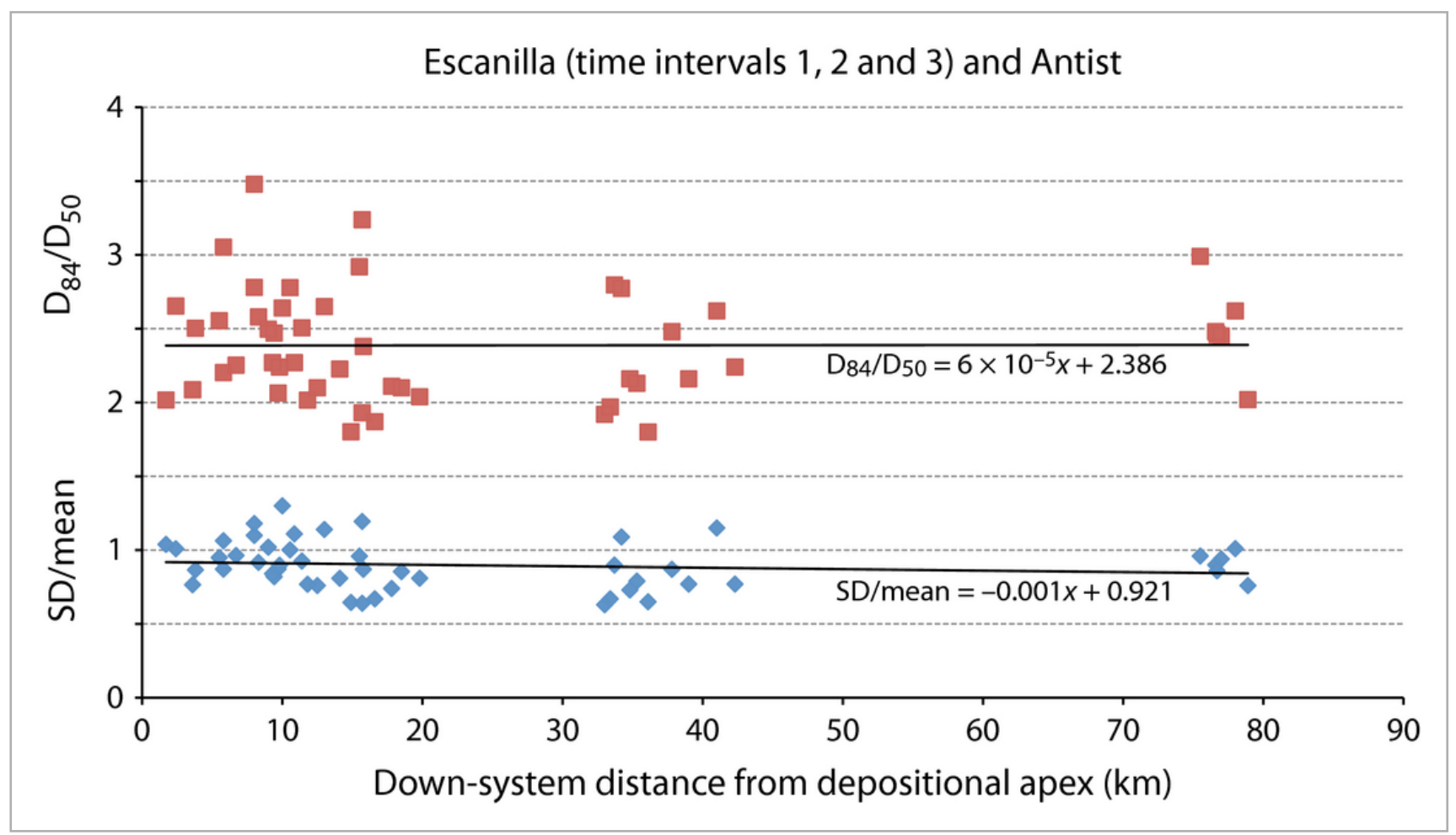

Figure 19.

Open in figure viewer

Down-system variation of the ratios $D_{84} / D_{50}$ and $\sigma / \mu$ for the mid-upper Eocene Escanilla palaeo-sediment routing system combined with the overlying Oligocene Antist system. There is no statistical change in either ratio in the down-system direction.

Focussing on the gravel-rich segment of the Escanilla palaeo-sediment routing system, the values of the 84th and 50th percentiles can be used to estimate the variation of the Pareto shape parameter $a$ in the down-system direction using equation (6). Average values of a range from 1.47 for time interval 1 , to 1.40 for time interval 2 and 1.30 for time interval 3, with an average $(n=100)$ for the entire Escanilla system of 1.40. There is no statistically significant variation in $a$ in the down-system direction within the terrestrial segment between the depositional apex and the gravel front (Fig. 20). 


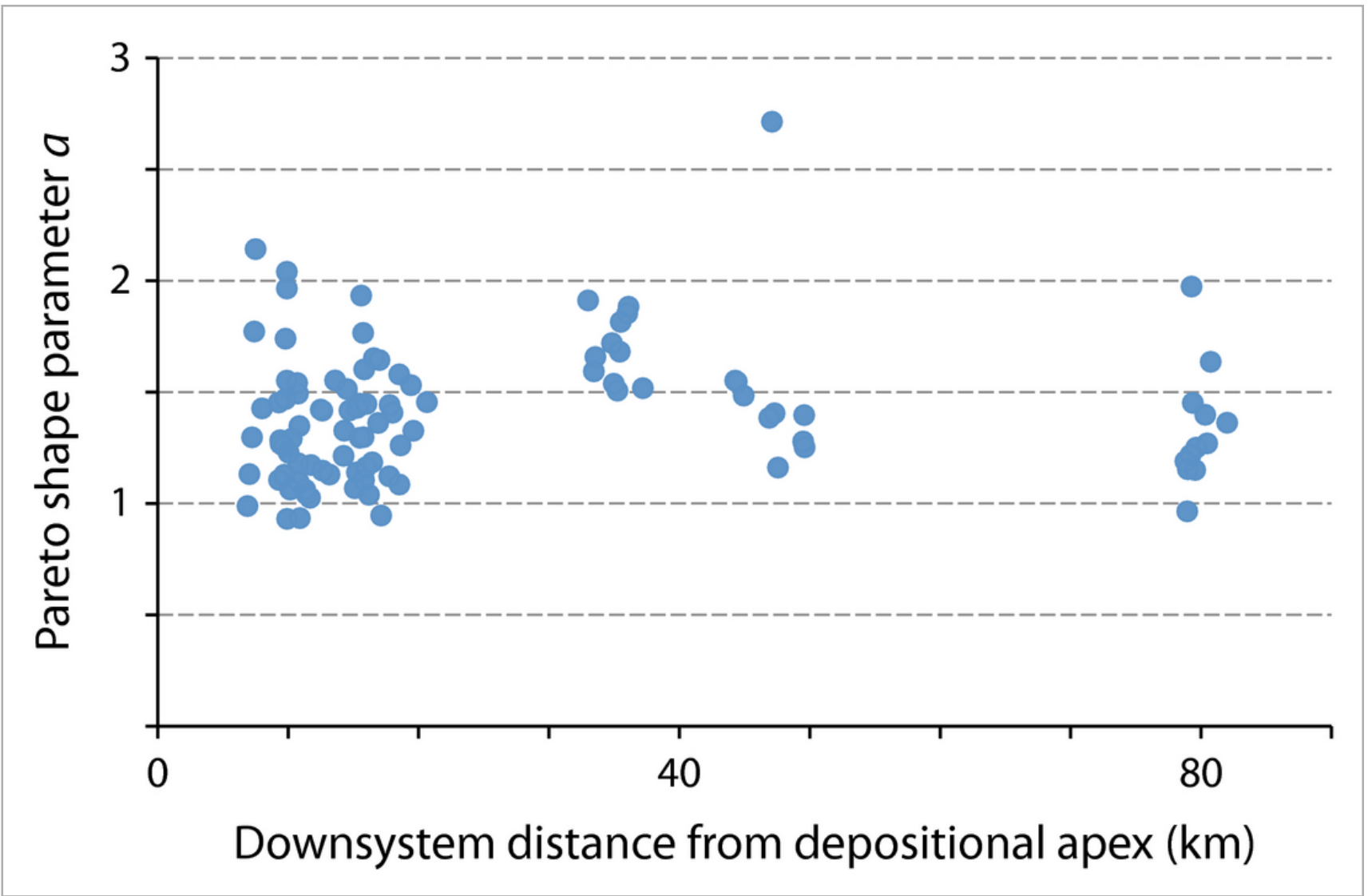

Figure 20.

Open in figure viewer

Down-system variation of the Pareto shape parameter $a$ in the segment from the depositional apex to the gravel front of the Escanilla palaeo-sediment routing system, for the combination of time intervals 1,2 and $3(n=100)$. There is no statistical change in $a$ in the down-system direction.

A goodness of fit analysis using the Kolmogorov-Smirnov statistic shows that the log-normal model fits the Escanilla data very well throughout the down-system distance of $80 \mathrm{~km}$. The truncated Pareto model has a similarly good fit with the coarser half of the grain size distributions throughout the down-system distance. However, the Weibull model exhibits a progressively worsening fit with increasing down-system distance (Fig. 21). There are few differences between the goodness of fit of the Weibull and log-normal models between the two main tributaries of the Escanilla system, the Sis and the Gurb (Michael et al., 2013, 2014) (Tables S10-S12). 


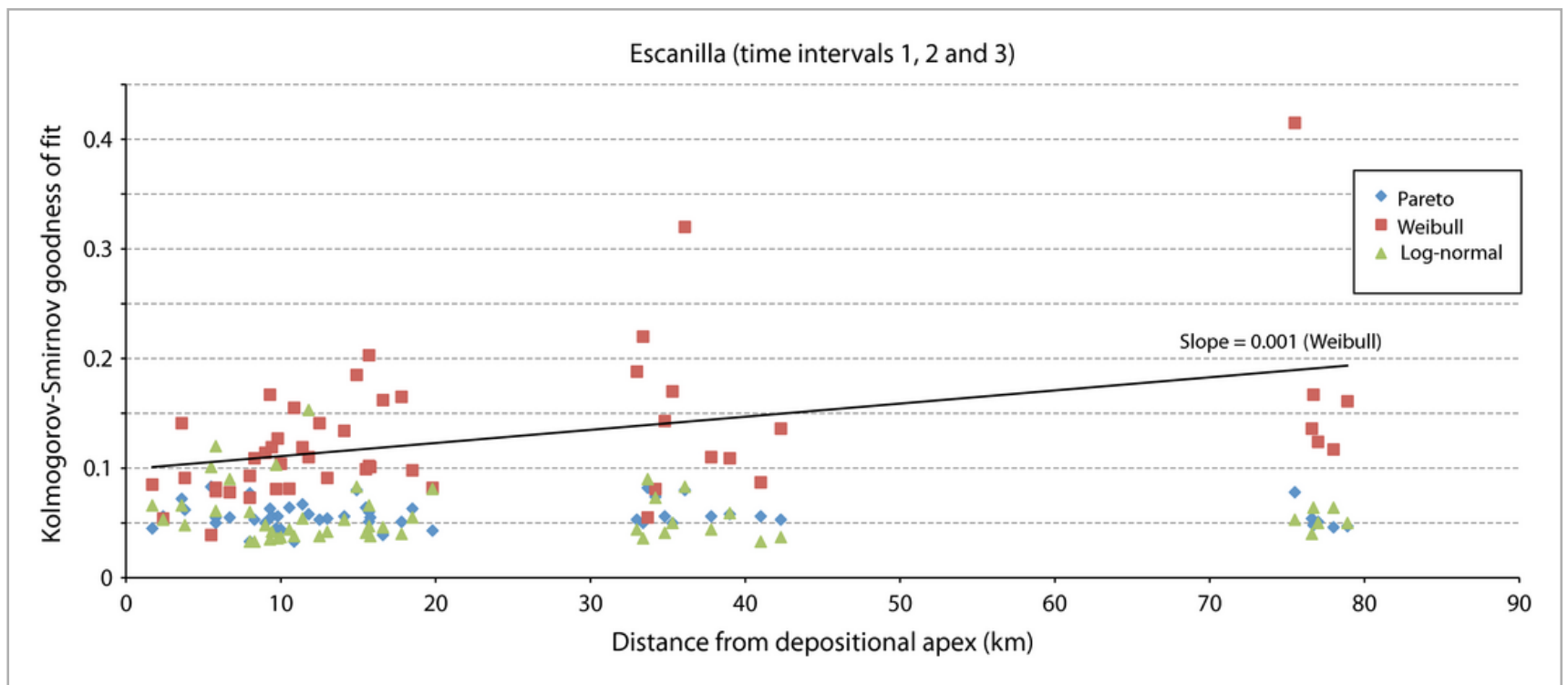

Figure 21.

Open in figure viewer

Kolmogorov-Smirnov goodness of fit statistic $D_{K S}$ as a function of down-system distance for the truncated Pareto, Weibull and log-normal models, using clast size data from the mid-upper Eocene Escanilla palaeo-sediment routing system.

The grain size data from the Oligocene Antist Group, which extend over a down-system distance of $35 \mathrm{~km}$, show no significant variation in the Pareto shape parameter (Fig. 22a) (Table S13). The clast size distributions are best fitted by the truncated Pareto model, but it is noticeable that the Weibull model provides a better fit than the log-normal model (Fig. 22b). This is in contrast to the Escanilla data where the truncated Pareto and log-normal models provide excellent fits and the Weibull model is distinctively inferior, particularly at large down-system distances (Fig. 21). This contrast in the statistical properties of particle size distributions in the Escanilla and Antist systems (Fig. 23) suggest either a change in the controlling factors responsible for the sediment supply (climate, topography, bedrock lithologies) or in the transport and depositional mechanisms of sediment between the two systems. 


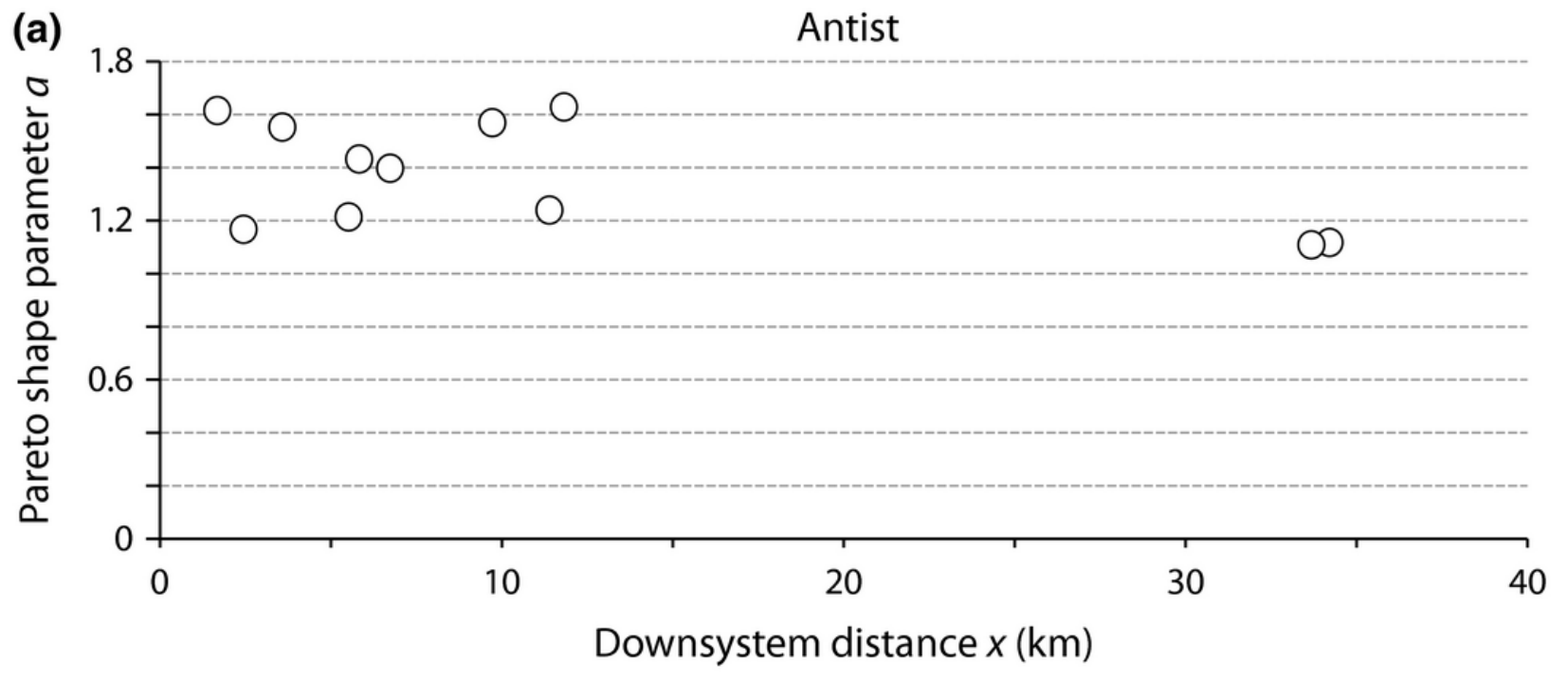

(b)

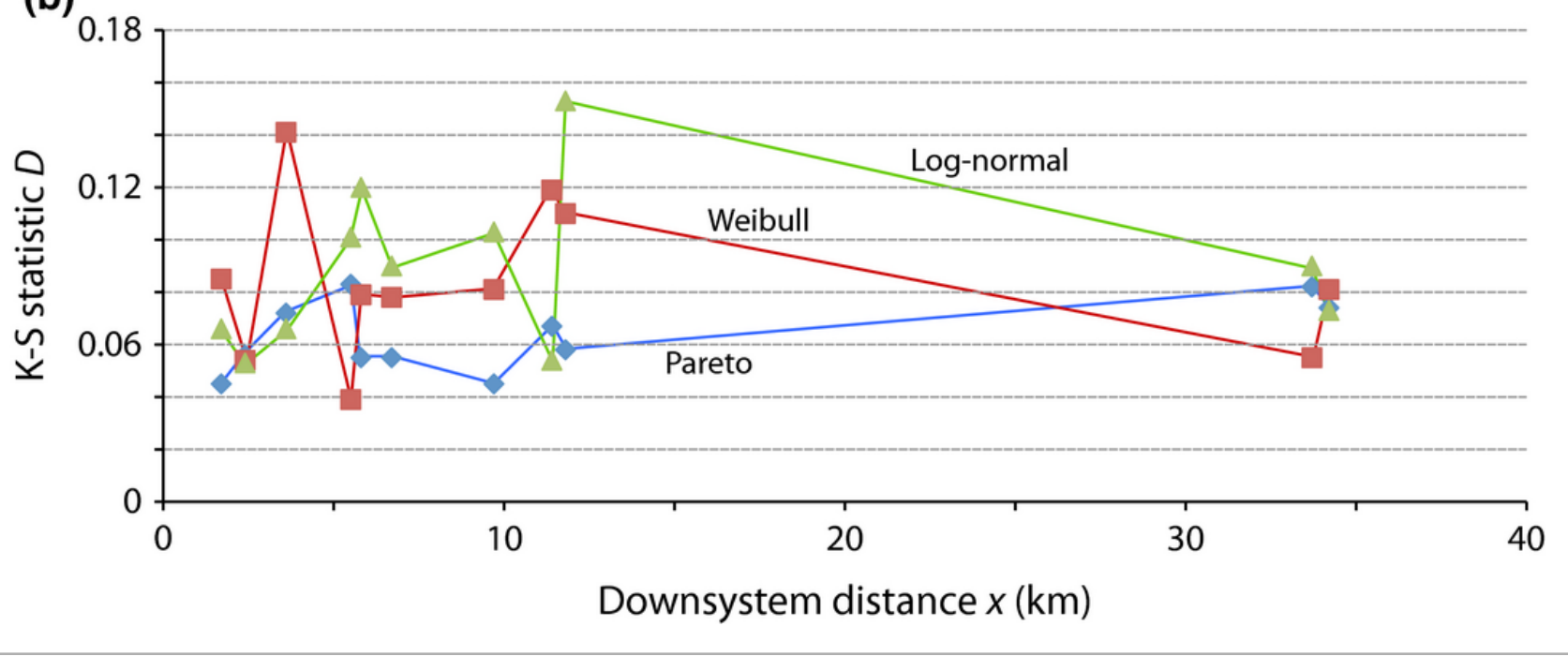

Figure 22.

Open in figure viewer

(a) Pareto shape parameter a as a function of down-system distance from the depositional apex for the Oligocene Antist palaeo-sediment routing system. (b) Kolmogorov-Smirnov goodness of fit statistic $D_{K S}$ as a function of down-system distance for the truncated Pareto, Weibull and lognormal models, using clast size data from the Oligocene Antist palaeo-sediment routing system. 


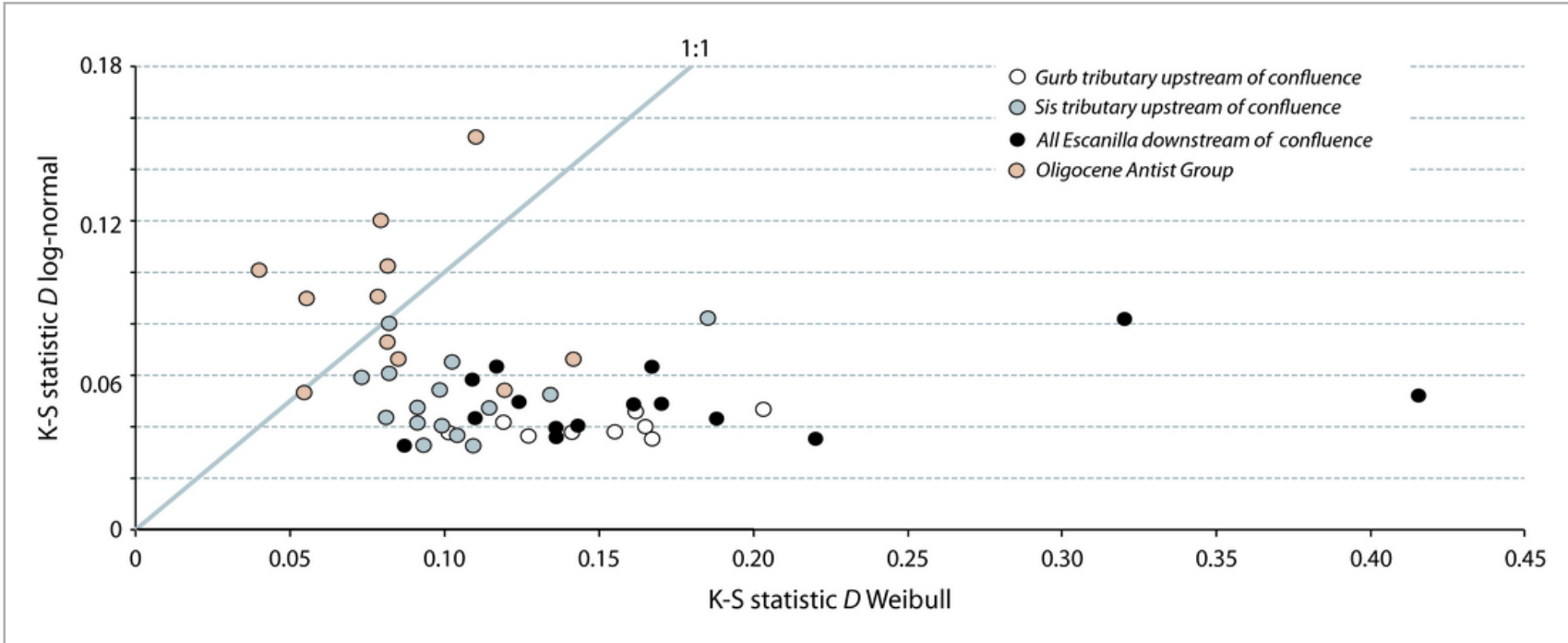

Figure 23.

Open in figure viewer

Kolmogorov-Smirnov goodness of fit statistic $D_{K S}$ for the log-normal model vs. the Weibull model, for the mid-upper Eocene Escanilla palaeo-sediment routing system and overlying Oligocene Antist system. Data from the Gurb and Sis tributaries, and the Escanilla system downstream of the confluence are shown separately. The log-normal model is strongly superior to the Weibull model for the Escanilla data, whereas the Weibull model is on average comparable to or superior for the Antist.

\section{Miocene-Pliocene fluvial gravels of the Great Plains, USA}

The relief of the Rocky Mountains was reduced following the Laramide orogeny ( ca. $40 \mathrm{Ma}$ ) by erosion in the hinterland and deposition of sediment across the Great Plains region (Swinehart et al., 1985; McMillan et al., 2006). During Miocene to late Pliocene time, gravel was spread from the Rocky Mountains as much as $600 \mathrm{~km}$ to the east across the Great Plains area (Fig. 24), depositing the Ogallala Group (18-6 Ma) and the erosionally overlying Broadwater Formation (3.7-2.5 Ma). The base of the Broadwater Formation is marked by an entrenched channel fill known as the Remsburg Ranch Beds (Swinehart \& Diffendal, 1987). Duller et al . (2012) analysed the grain size characteristics of these stratigraphic units in exposures along the flanks of the North Platte River. 
(a)

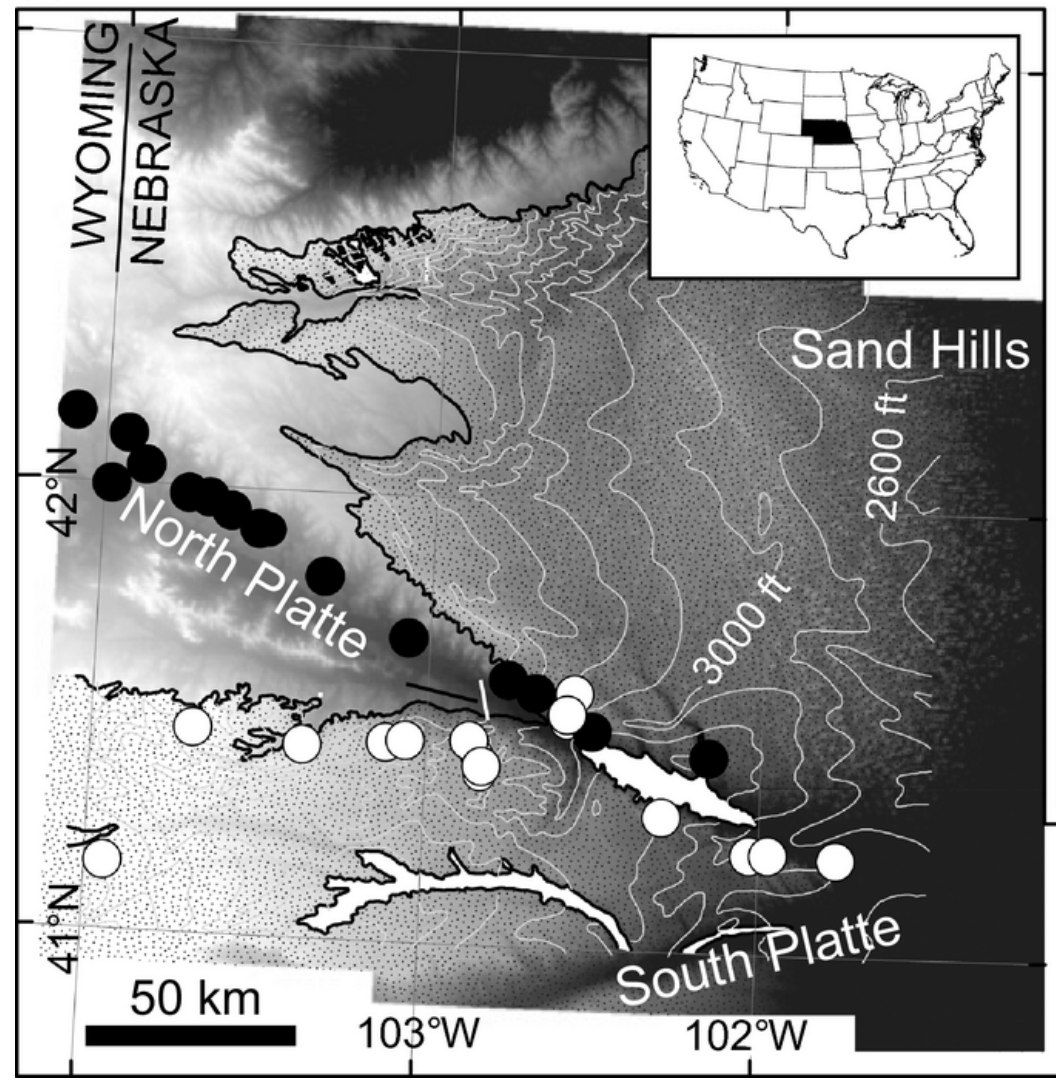

(b)

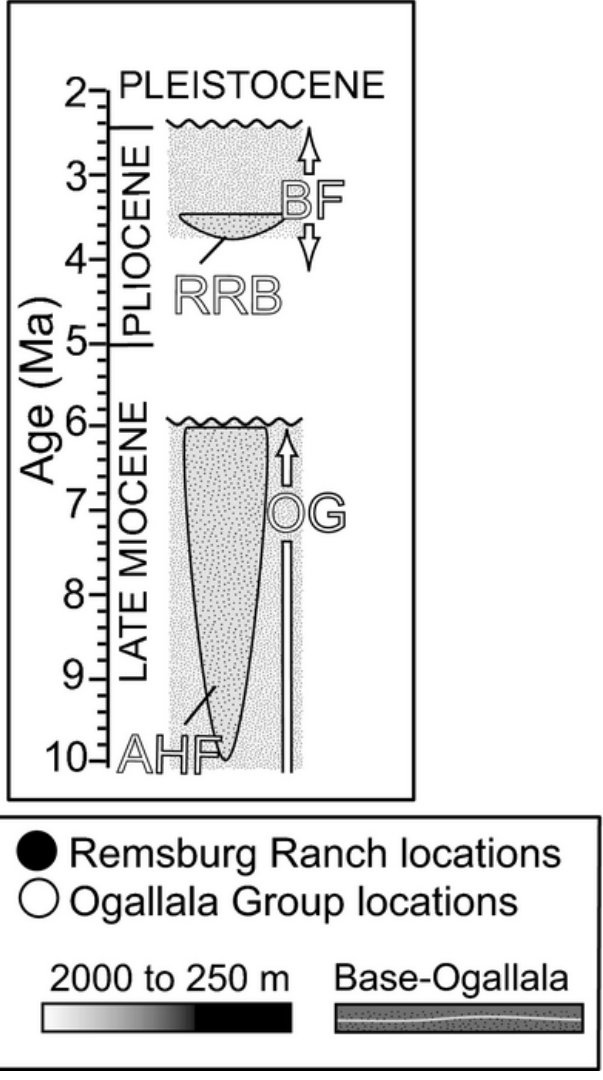

\section{Figure 24.}

Open in figure viewer

(a) Location map, showing granulometric analysis sites in the Ogallala and Remsburg Ranch beds. White lines represent base-of-Ogallala structure contours; black lines represent edge of the Ogallala outcrop. (b) Fluvial succession of the Nebraskan Plains from 10 Ma to present; OG, Ogallala Group; AHF, Ash Hollow Formation; BF, Broadwater Formation; RRB, Remsburg Ranch Beds, following Swinehart et al . (1985); Swinehart \& Diffendal (1987).

Using clast size data collected using the Wolman (1954) method, $D_{84} / D_{50}$ values for the Miocene to late Pliocene (Ash Hollow Formation of the Ogallala Group, base of Remsburg Ranch Beds, top of Remsburg Ranch Beds, Broadwater Formation) show no clear down-system trend (Tables S8 and S9). Values of the Pareto shape parameter a calculated from the 84th and 50th percentiles using equation (2) or (6), show no discernible down-system trend in values, but distal values tend to be higher than proximal, particularly in the case of the photo count data for the Broadwater Formation (Fig. 25). 

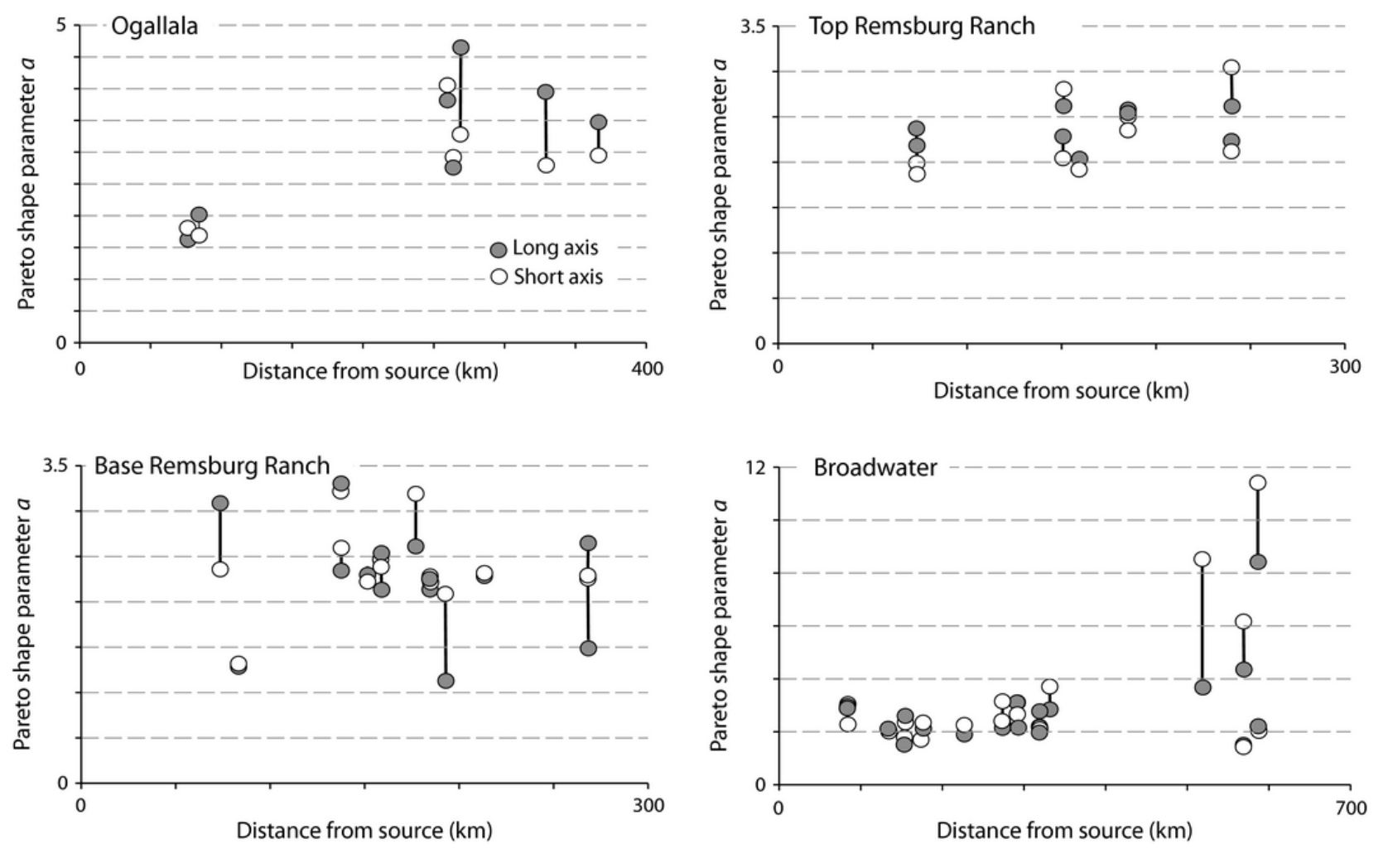

\section{Figure 25.}

\section{Open in figure viewer}

Down-system variation of the Pareto shape parameter a for the Ogallala, base Remsburg Ranch, top Remsburg Ranch and Broadwater units of the Miocene-Pliocene of the Great Plains, Nebraska, USA, calculated from the 84th and 50th percentiles of the long and short axes of clasts using the Wolman clast count and digital image methods. Results for long and short axes at the same station are connected by vertical bars.

Taking the Miocene-Pliocene of the Great Plains as a whole, it is notable that the Pareto shape parameter $a$ is significantly higher than in the cases of material in the erosional source regions in Italy or constituting proximal debris flows in Owens Valley. Average values range from 2.79-3.19 (A and B axes) for the Ogallala, to 2.26 - 2.37 for the base Remsburg Ranch, to $2.29-2.38$ for the top Remsburg Ranch, and $2.77-3.31$ for the Broadwater. The markedly different range of values of a compared to that of the sediment in the erosional engine indicates an important change in the spread of the grain size distribution, which most likely in turn reflects transport and depositional processes.

We calculated the Kolmogorov-Smirnov goodness of fit statistic for a selection of stratigraphic units in the Miocene-Pliocene of the Great Plains. Statistics were calculated for the geometric mean of the long $(A)$ and short $(B)$ axes of clasts $(\sqrt{A B})$. The Ogallala (Ash Hollow Formation) clast size data collected using the Wolman (1954) method are equally well fitted by the truncated Pareto model for the coarse half of the clast size distribution ( $D_{K S}=0.063$ ) and the log-normal model for the full clast size distribution ( $D_{K S}=0.068$ ), but the Weibull model provides a poor fit. There is no recognizable down-system trend in $D_{k s}$. Similarly, the Wolman clast size data from the Remsburg Ranch Beds are well fitted by the truncated Pareto model ( $D_{K S}=0.060$ ) and particularly by the log-normal model ( $D_{K S}=0.047$ ), but the Weibull model gives a poor fit. There is no down-system trend in $D_{K S}$ in the Remsburg Ranch Beds

\section{Discussion and Conclusions}


The particle size distribution of regolith and sediment has been analysed from a number of settings within both the net erosional source region or 'erosional engine' and in the net depositional zone. Regolith on a variety of bedrock lithologies, bedload material in trunk channels and sediment at the outlet points of upland catchments in southern Italy have average Pareto shape parameters ranging from 1.22 to 1.37 (Fig. 26). The Pareto shape parameter typical of exported sediment is therefore well constrained. The debris flows of Shepherd Creek fan, Owens Valley, eastern California, which were emplaced in one cycle of evacuation from upstream catchments, vary in their Pareto shape parameter between levees and channels in the proximal fan region, but converge to a value of about 1.3 in the distal fan. This value is indistinguishable from that of the regolith and sediment stored in upland catchments. Historical debris flows in the Owens Valley area, ranging back to $>100 \mathrm{ka}$, have Pareto shape parameter values of 1.53 and 1.24 for channels and levees, respectively, suggesting that the sediments of former debris flow channel areas are modified over time, becoming enriched in finer grain sizes, whereas levees are little modified.

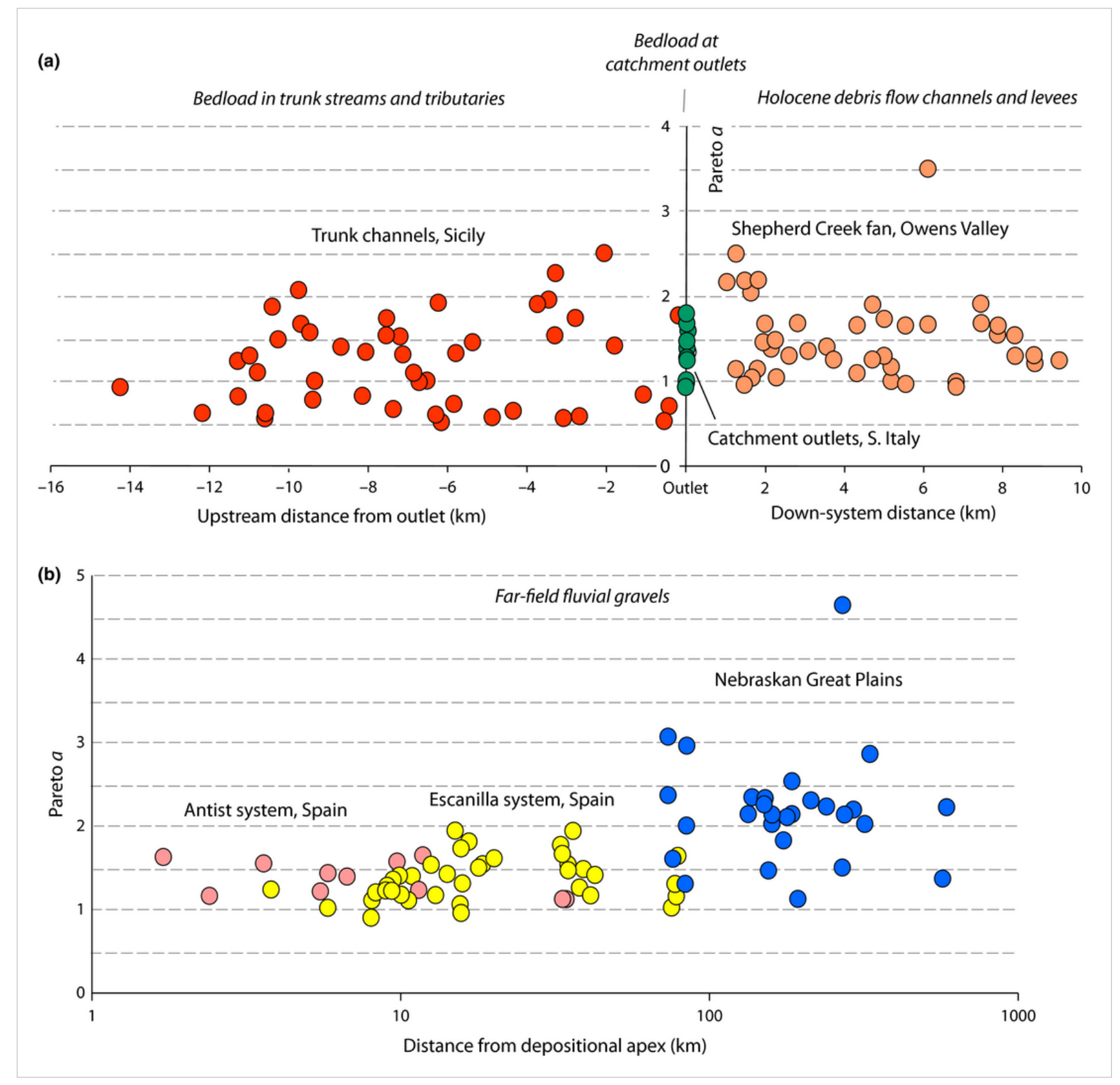

\section{Figure 26.}

Open in figure viewer

Compilation of estimates of the Pareto shape parameter a as a function of down-system 
flow deposits. (b) Fluvial gravels, shown with a logarithmic scale for the down-system distance from the depositional apex. The average value of Pareto a increases with down-system distance, most likely driven by the loss of coarse particles by selective deposition.

Although bedrock lithology affects the statistical properties of regolith, with significant differences between catchments in carbonate terrains compared to those underlain by flysch (mudstones and sandstones) and granites/gneisses, the log-normal model provides a good fit with field data for the particle size distribution of the entire range of gravel, and the Pareto model provides an equally good fit for the coarser half of the gravel range.

A similar situation is found with proximal Quaternary debris flows but particle size distributions differ depending on whether clasts are sampled from lateral levees or central channels. Whereas both levees and channels are equally well fitted by the Weibull model, the levees of debris flows with ages going back to ca. 100 ka are significantly better fitted by a log-normal model than the associated channels. Likewise, the truncated Pareto model shows a good fit with debris flow levees at the present day and historically, while failing to fit well the associated debris flow channels. The fundamental reason for the differences between the clast size distributions of lateral levees and central channels has its origin in the internal dynamics of mass flows, which cause an advection of larger clasts to the front of the flow and then laterally into levees (Johnson et al., 2012). Over time, the fan surface, particularly the low topography of debris flow channels, is infiltrated by fines.

The key question for those interested in the grain size fractionation in sediment routing systems is whether the particle size statistics of materials found in the 'erosional engine', or emplaced by debris flows in proximal fan positions in one cycle of evacuation, are significantly different to those sediments that have undergone far-field transport. To answer this question, we have investigated the gravelly EoceneOligocene Escanilla and Antist palaeo-sediment routing systems of the southern flank of the central Pyrenees and the Miocene-Pliocene fluvial sediments dispersed from the Rocky Mountains across the Great Plains, USA.

The full grain size mix of the Escanilla system averaged over long time periods ( $>1 \mathrm{Myr}$ ) is obtained by inverting the grain size fractions measured in stratigraphy. Using this method and adopting the Pareto model, a varies between 0.97 and 1.45 for the three time intervals analysed, with an average for the entire Escanilla system of 1.12. Time interval 3, which experienced the greatest influx of coarse sediment during the evolution of the Escanilla system, has a value of $a<1$, indicating significant enrichment in coarse clasts relative to fine, which can be attributed to the effects of selective deposition in a rapidly subsiding basin combined with hydraulic sorting. In the Antist palaeo-sediment routing system, the Pareto shape parameter varies between 1.11 and 1.62, with an average of 1.37 , which is significantly higher than the average for the Escanilla system, indicating a greater concentration of smaller clasts in the Antist system.

Although grain sizes fine down-system as expected, there is no down-system variation of $D_{84} / D_{50}$ or $\sigma / \mu$ in the Escanilla and Antist palaeo-sediment routing systems, showing that these ratios may be used as similarity parameters. Over a down-system distance of $80 \mathrm{~km}$ in the Escanilla palaeo-sediment routing system, the log-normal model provides an excellent fit across the entire gravel grade, and the truncated Pareto model gives an equally good fit for the coarser half of the gravel-grade size distribution. Whereas the Weibull model gives a moderately good fit in proximal fluvial gravels, the fit worsens down-system. Over a down-system distance of $34 \mathrm{~km}$ in the Antist palaeo-sediment routing system, the truncated Pareto model provides the best fit, the Weibull model is moderately good, whereas the log-normal model is the least good of the three. Only the Oligocene Antist system has size distributions where the Weibull model is a closer fit than the log-normal model, indicating a significant difference between the extrinsic and/or intrinsic factors governing the sediment supply, size-selective deposition and hydraulic sorting of the Escanilla and Antist systems. 
In the Miocene-Pliocene fluvial deposits of the Great Plains, the average Pareto shape parameter a derived from long-axis data varies from 3.19 in the Ogallala Formation, to 2.26, 2.38 and 2.77 in the Basal Remsburg Ranch Beds, top Remsburg Ranch Beds and Broadwater Formation respectively. Values for the short axis are 2.79, 2.37. 2.29 and 3.31 respectively. A sample of clast size data obtained using the Wolman (1954) method based on the geometric mean from the Ogallala Group and the Remsburg Ranch Beds yields average Pareto shape parameter values of 2.43 and 2.05 respectively. All these values are considerably in excess of the values associated with the erosional engine and the Escanilla-Antist systems, and indicates important fractionation processes during far-field transport. The high value of $a$ indicates significant loading of the particle size distribution with fine grains. This may be due to the upstream extraction of large grains from the surface flows, leaving it enriched in fine particles. This is a reciprocal process compared to the Escanilla, demonstrating the combined effect of far-field transport and selective deposition in sediment routing systems. In combination with a relatively high value of $a$, the Great Plains full clast size distributions are strongly log-normal, and the coarser half of the clast size distributions are well fitted by the truncated Pareto model, whereas the Weibull model is a poor fit.

Ibbeken (1983) found that although jointed and weathered bedrock in southern Calabria, Italy, had a Rosin (Weibull) distribution, gravelly sediments sampled near the mouths of rivers where they enter the lonian Sea, up to $20 \mathrm{~km}$ distant, were commonly bimodal with a sand fraction that was log-normally distributed. The log-normal property of sands is most likely imparted by transport processes causing hydraulic sorting (Middleton, 1976). A comparison of the goodness of fit of sediment in the erosional engine, at catchment outlets and as far-field fluvial gravel shows that the Rosin (Weibull) distribution is the poorest fit, particularly in far-field gravels (Fig. 27). The log-normal distribution and the truncated Pareto distribution improve in the closeness of their fit with field data with increasing mobilization and transport. This suggests that increasing fluvial transport enhances the log-normality of clast size distributions, as suggested by Krumbein (1938) and McEwen et al . (1959)

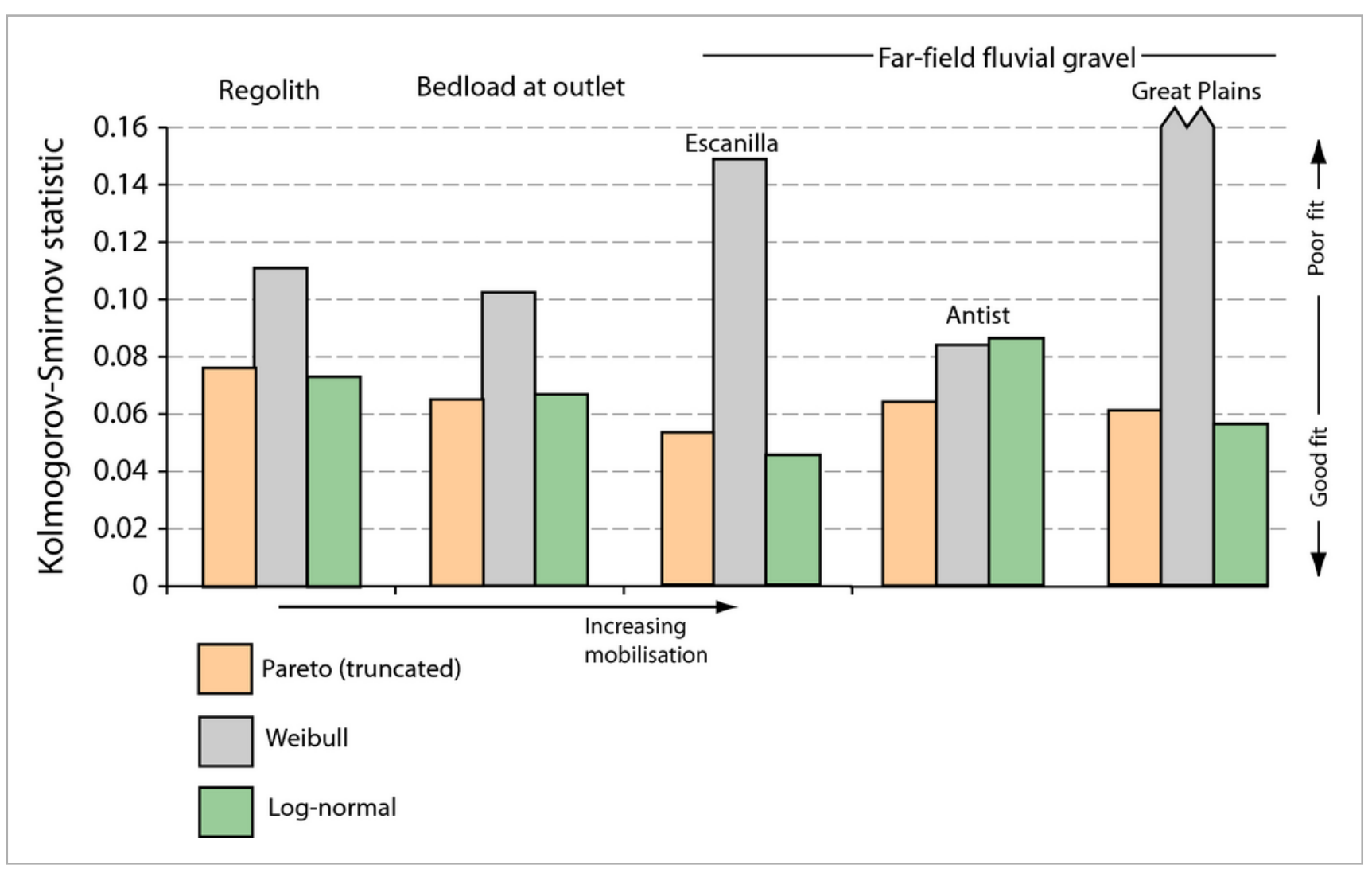

\section{Figure 27.}

Open in figure viewer 
Kolmogorov-Smirnov goodness of fit statistic $D_{K S}$ for weathering products (regolith in Basilicata, Campania and Calabria, southern Italy), coarse bedload in channels at catchment outlets (Pagliara, Fiumedinisi and Agro catchments, Sicily) and far-field fluvial gravels (Escanilla palaeosediment routing system, south-central Pyrenees, Spain; Antist palaeo-sediment routing system, south-central Pyrenees and Ebro Basin, Spain; Ogallala Group (Ash Hollow Formation) and Remsburg Ranch Beds, Nebraska, USA). Whereas the Weibull model shows a worsening fit with degree of sediment mobilization, the truncated Pareto and log-normal models show an improved fit with increasing mobilization. Note that the Pareto statistics refer to the coarser half of the clast size distribution.

Although fragment sizes in sedimentary materials from regolith to far-field gravel have a broad lognormality, increasing down-system, the Pareto model, base truncated to account for the finite minimum grain size (scale parameter $k_{P}$ ), also provides a good fit with the coarser half of the clast size distribution of field data from source to sink, and has the advantage of having a shape parameter that is potentially diagnostic of sediment transport and depositional processes. This shape parameter is well constrained in the erosional engine. On release into sediment transport systems, the clast size distribution may evolve predictably, moderated by the role of selective deposition. At short transport distances, shown by the Escanilla system, rapid deposition in proximal positions causes the extraction of the coarsest grains into stratigraphy, causing the shape parameter a to decrease from the value associated with the sediment supply from the erosional engine (Fig. 28). At longer transport distances, or at positions further downsystem in terms of the total mass balance (Martin et al., 2009; Michael et al., 2013), shown by the Great Plains system, the clast size distribution is enriched in relatively small particles compared to the sediment supply because of up-system selective deposition combined with abrasion during transport, increasing the shape parameter $a$. Consequently the Pareto shape parameter can potentially be used as an indication of proximality. Further studies should shed light on whether this evolutionary pathway is a generic property of sediment routing systems. 


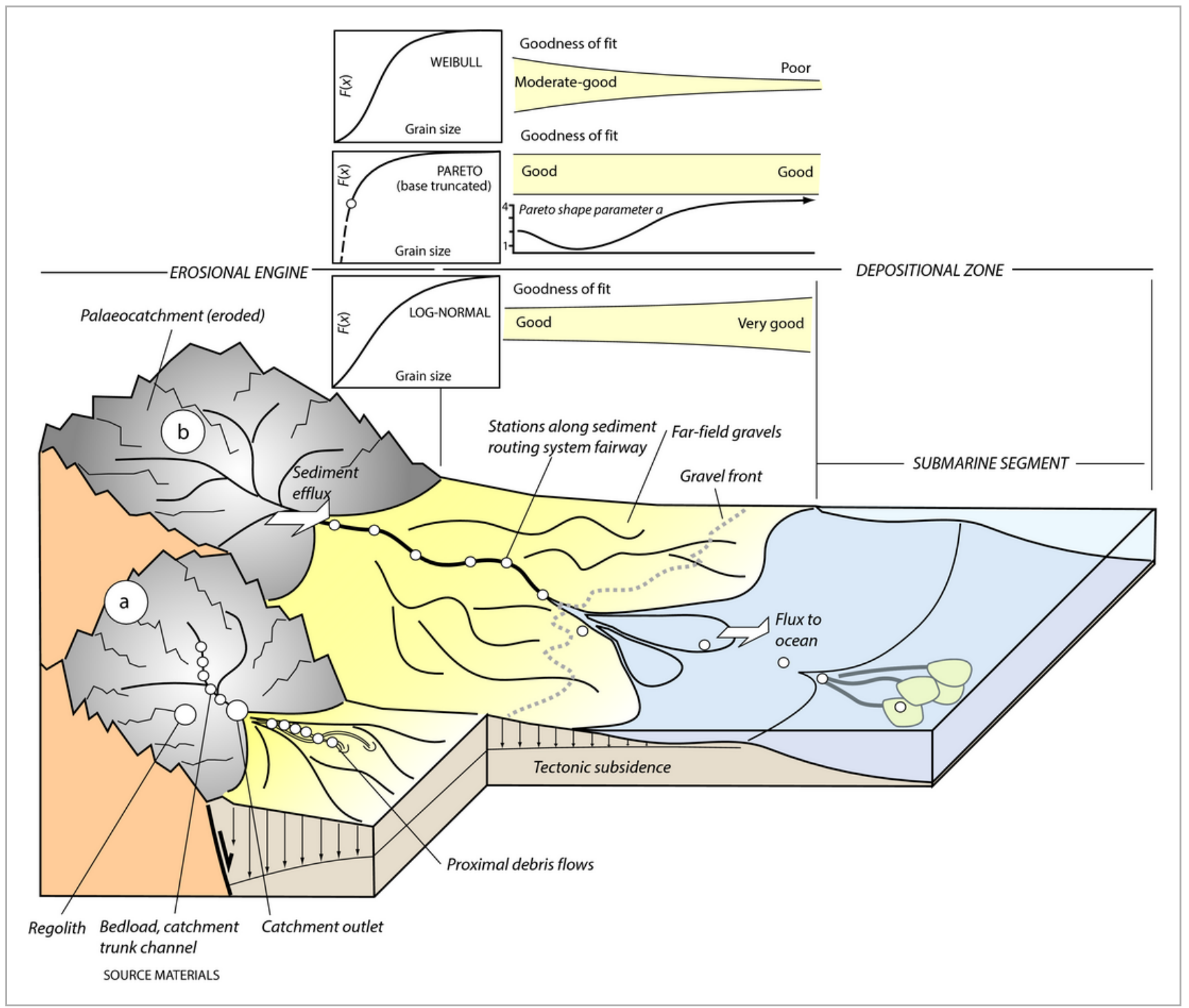

Figure 28.

\section{Open in figure viewer}

Schematic sediment routing systems showing the context of the samples analysed. (a) Small coarse grained catchment-fan system with samples collected from regolith, channel bedload and sediment at the catchment outlet, which are indistinguishable from proximal debris flows in terms of Pareto shape parameter a . (b) Large palaeo-sediment routing system with a catchment not preserved in the geological record. Stations are distributed along the sediment routing system fairway in the down-system direction. The truncated Pareto, Weibull and log-normal models are shown as cumulative distribution functions and in terms of goodness of fit, evaluated using the Kolmogorov-Smirnov statistic. The down-system variation of the Pareto shape parameter $a$ is based on a compilation of all datasets and is partly speculative.

Despite the large down-system changes in mean grain size and gravel percentage from source region to depositional sink, particle size distributions appear to maintain log-normality over a wide range of transport distance. Consequently, full grain size distributions can be predicted within the terrestrial segment of sediment routing systems given simple laws of downstream fining. These full grain size distributions may help to inform the estimation of hydraulic properties of aquifers and oil and gas reservoirs, such as porosity and permeability. Use of statistical models therefore enables down-system fractionation of sediment 
released from source regions to be better understood and predicted and is a potentially valuable tool in source-to-sink approaches to basin analysis.

In outlook, fractionation of grain size in sediment routing systems should ideally be viewed in terms of the mass balance coordinate $X$ rather than in terms of down-system distance (Paola \& Martin, 2012), but this requires the total sediment budget to be known or approximated. In addition, documentation of the grain size properties of sediment routing systems from different climatic, topographic and tectonic settings is required before the results presented here can be viewed as generic. Finally, it should be remembered that our analysis concerns the size distributions of gravel-grade sediment in the terrestrial segment of the sediment routing system, rather than the full grain size spectrum extended into the marine segment

\section{Acknowledgements}

We are grateful for the generous support of Statoil for a generic programme of sediment routing system research led by PAA. Grain size data were also collected during the tenure of research studentships by DRB and MD supervised by ACW. Work on the Escanilla system was carried out by NAM, partly funded by Saudi-Aramco. Grain size data from the Great Plains were collected by RAD and ACW assisted by undergraduates Landey Patton and Will Neal. We are grateful for the constructive reviews of Chris Paola (Minnesota) and Zane Jobe (Stanford).

\section{References}

Allen, P.A. \& Allen, J.R. (2013) Basin Analysis: Principles and Application to Petroleum Play Assessment, 3rd edn. Wiley-Blackwell, Oxford.

SFX

Allen, P.A. \& Heller, P.L. (2012) The timing, distribution and significance of tectonically generated gravels in terrestrial sediment routing systems. In: Tectonics of Sedimentary Basins: Recent Advances (Ed. by C. Busby \& A. Azor), pp. 111-130. Wiley Blackwell, Oxford.

CrossRef | SFX

Allen, P.A., Armitage, J.J., D’Arcy, M., Roda-Boluda, D. \& Whittaker, A.C. (2015) Fragmentation model for the grain size mix of sediment supplied to basins. J. Geol., 123, 405-427.

CrossRef | Web of Science® Times Cited: 3 | ADS | SFX

Blatt, H., Middleton, G. \& Murray, R. (1980) Origin of Sedimentary Rocks. Prentice-Hall, New Jersey. SFX

Burt, T.P. \& Allison, R.J. (2010) Sediment cascades. In: Sediment Cascades in the Environment: An Integrated Approach (Ed. by T.P. Burt \& R.J. Allison), pp. 1-15. John Wiley and Sons, Chichester.

CrossRef | SFX 
Carvajal, C. \& Steel, R. (2012) Source-to-sink sediment volumes within a tectono-stratigraphic model for a Laramide shelf-to-deep-water basin: Methods and results. In: Tectonics of Sedimentary Basins: Recent Advances (Ed. by C. Busby \& A. Azor Perez), pp. 131-151. Wiley-Blackwell, Oxford, UK.

CrossRef | SFX

Coney, P.J., Munoz, J.A., McClay, K.R. \& Evenchick, C.A. (1996) Syntectonic burial and post-tectonic exhumation of the southern Pyrenees foreland fold-thrust belt. J. Geol. Soc., 153(9), 9-16.

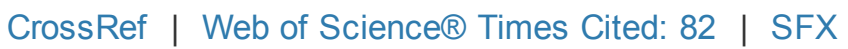

Covault, J.A., Normark, W.R., Romans, B.W. \& Graham, S.A. (2007) Highstand fans in the California Borderland: the overlooked deep-water depositional system. Geology, 35, 783-786.

CrossRef | Web of Science $®$ Times Cited: 98 | ADS | SFX

Covault, J.A., Romans, B.W., Graham, S.A., Fildani, A. \& Hilley, G.E. (2011) Terrestrial source to deep-sea sink sediment budgets at high and low sea levels: insights from tectonically active southern California.

Geology, 39, 619-622.

CrossRef | Web of Science® Times Cited: 30 | SFX

D'Arcy, M., Roda Boluda, D.C., Whittaker, A.C. \& Carpineti, A. (2015) Dating alluvial fan surfaces in Owens Valley, California, using weathering fractures in boulders. Earth Surf. Proc. Land., 487-501. doi: 10.1002/esp.3649.

Wiley Online Library | Web of Science ${ }^{\circledR}$ Times Cited: 3 | ADS | SFX

Dacey, M.F. \& Krumbein, W.C. (1979) Models of breakage and selection for particle size distributions. Math. Geol., 11(2), 193-222.

CrossRef | Web of Science ${ }^{\circledR}$ Times Cited: 4 | SFX

Deb, D. \& Sen, A.K. (2013) Rosin's law and size distribution of particles in regolith-like samples - an analysis. Planet. Space Sci., 82-83, 79-83. doi: 10.1016/j.pss.2013.03.014.

CrossRef | Web of Science ${ }^{\circledR}$ Times Cited: 1 | ADS | SFX

Dreyer, T., Corregidor, J., Arbues, P. \& Puigdefabregas, C. (1999) Architecture of the tectonically influenced Sobrarbe deltaic complex in the Ainsa Basin, northern Spain. Sed. Geol., 127, 127-169.

CrossRef | Web of Science ${ }^{\circledR}$ Times Cited: 73 | ADS | SFX

Dühnforth, M., Densmore, A.L., Ivy-Ochs, S., Allen, P.A. \& Kubic, P.W. (2007) Timing and patterns of debris flow deposition on Shepherd and Symmes Creek fans Owens, Valley, California, deduced from cosmogenic ${ }^{10}$ Be. J. Geophys. Res. Earth Surf., 112, F3. doi: 10.1029/2006JF000562.

Wiley Online Library | Web of Science® Times Cited: 21 | ADS | SFX

Duller, R.A., Whittaker, A.C., Fedele, J.J., Springett, J., Smithells, R. \& Allen, P.A. (2010) From grain size to tectonics. J. Geophys. Res. Earth Surf., 115, F03022. doi: 10.1029/2009JF001495.

Wiley Online Library | Web of Science® Times Cited: 27 | ADS | SFX

Duller, R.A., Whittaker, A.C., Swinehart, J.B., Armitage, J.J., Sinclair, H.D., Bair, A.R. \& Allen, P.A. (2012) Abrupt landscape change post $6 \mathrm{Ma}$ on the central Great Plains, USA. Geology, 40, 871-874.

CrossRef | Web of Science® Times Cited: 24 | SFX

Eberl, D.D., Drits, V.A. \& Srodon, J. (1998) Deducing growth mechanisms for minerals from the shapes of crystal size distributions. Am. J. Sci., 298, 499-533. 
Fedele, J.J. \& Paola, C. (2007) Similarity solutions for fluvial sediment fining by selective deposition. J. Geophys. Res., 112, F02038. doi: 10.1029/2005JF000409.

Wiley Online Library | Web of Science® Times Cited: 34 | ADS | SFX

Green, J.C. (2003) The precision of sampling grain-size percentiles using the Wolman method. Earth Surf. Proc. Land., 28, 979-991.

Wiley Online Library | Web of Science® Times Cited: 13 | ADS | SFX

Hampson, G.J., Duller, R.A., Petter, A.L., Robinson, R.A.J. \& Allen, P.A. (2014) Mass balance constraints on stratigraphic interpretation of linked alluvial-coastal-shelfal deposits: Upper Cretaceous Castlegate Sandstone, Blackhawk Formation, Star Point Sandstone and Mancos Shale, Utah, and Colorado, USA. J. Sediment. Res., 84, 935-960.

CrossRef | Web of Science® Times Cited: 6 | ADS | SFX

Hartmann, W.K. (1969) Terrestrial, lunar, and interplanetary rock fragmentation. Icarus, 10, 201-213.

CrossRef | Web of Science ${ }^{\circledR}$ Times Cited: 180 | ADS | SFX

Ibbeken, H. (1983) Jointed source rock and fluvial gravels controlled by Rosin's law: a grainsize study in Calabria, south Italy. J. Sediment. Petrol., 53, 1213-1231.

Web of Science® Times Cited: 31 | SFX

Johnson, C.G., Kokelaar, B.P., Iverson, R.M., Logan, M. \& LaHusen, R.G. (2012) Grainsize segregation and levee formation in geophysical mass flows. J. Geophys. Res., 117, F01032. doi: 10.1029/2011JF002185.

Wiley Online Library | Web of Science® Times Cited: 65 | ADS | SFX

Kittleman, L.R. (1964) Application of Rosin's distribution in size-frequency analysis of clastic rock. J. Sediment. Petrol., 34/3, 483-502.

SFX

Krumbein, W.C. (1938) Size-frequency distributions of sediments and the normal phi curve. J. Sediment. Petrol., 8, 84-90.

CrossRef | SFX

Krumbein, W.C. \& Tisdel, F.W. (1940) Size distributions of source rocks of sediments. Am. J. Sci., 238, 296305.

CrossRef | SFX

Le, K., Lee, J., Owen, L.A. \& Finkel, R. (2007) Late Quaternary slip rates along the Sierra Nevada frontal fault zone, California: slip partitioning across the western margin of the Eastern California Shear Zone, Basin and Range Province. Geol. Soc. Am. Bull., 119, 240-256.

CrossRef | Web of Science® Times Cited: 31 | ADS | SFX

Leopold, L.B. (1970) Am improved method for size distribution of stream gravel bed. Water Resour. Res., 6/5, 1357-1366.

Wiley Online Library | Web of Science® Times Cited: 71 | ADS | SFX

Martin, J., Paola, C., Abreu, V., Neal, J. \& Sheets, B. (2009) Sequence stratigraphy of experimental strata under known conditions of differential subsidence and variable baselevel. Bull. Am. Assoc. Petrol. Geol., 93, 503-533. 
McEwen, M.C., Fessenden, F.W. \& Rogers, J.J.W. (1959) Texture and composition of some weathered granites and slightly transported arkosic sands. J. Sediment. Petrol., 29, 477-492.

CrossRef | ADS | SFX

McMillan, M.E., Heller, P.L. \& Wing, S.L. (2006) History and causes of post-Laramide relief in the Rocky Mountain orogenic plateau. Geol. Soc. Am. Bull., 118, 393-405.

CrossRef | Web of Science $®$ Times Cited: 71 | ADS | SFX

Mellere, D. (1993) Thrust-generated, back-fill stacking of alluvial fan sequences, south-central Pyrenees, Spain (La Pobla de Segur Conglomerates). In: Tectonic Controls and Signatures in Sedimentary Successions (Ed. by Frostick L.E. \& Steel R.J.), Spec. Publ. Int. Assoc. Sediment . 20, 259-276.

SFX

Michael, N.A. (2013) Functioning of an ancient sediment routing system, the Escanilla Formation, Southcentral Pyrenees, PhD dissertation. Imperial College, London.

SFX

Michael, N.A., Whittaker, A.C. \& Allen, P.A. (2013) The functioning of sediment routing systems using a mass balance approach: example from the Eocene of the southern Pyrenees. J. Geol., 121 (6), 581-606.

CrossRef | Web of Science ${ }^{\circledR}$ Times Cited: 9 | ADS | SFX

Michael, N.A., Whittaker, A.C., Carter, A. \& Allen, P.A. (2014) Volumetric budget and grain-size fractionation of a geological sediment routing system: Eocene Escanilla Formation, South-Central Pyrenees. Geol. Soc. Am. Bull., 126, 585-599.

CrossRef | Web of Science ${ }^{\circledR}$ Times Cited: 7 | SFX

Middleton, G.V. (1976) Hydraulic interpretation of sand size distributions. J. Geol., 84, 405-426.

CrossRef | Web of Science ${ }^{8}$ Times Cited: 165 | ADS | SFX

Moore, J.G. (1981) Geologic map of the Mount Whitney quadrangle, Inyo and Tulare counties, California. In U.S. Geological Survey, Geologic Quadrangle 1545.

Paola, C. \& Martin, J.M. (2012) Mass balance effects in depositional systems. J. Sediment. Res., 82, 435450.

CrossRef | Web of Science® Times Cited: 17 | SFX

Paola, C., Heller, P.L. \& Angevine, C.L. (1992) The large-scale dynamics of grain-size variation in alluvial basins, 1: Theory. Basin Res., 4, 73-90.

Wiley Online Library | SFX

Robinson, R.A.J. \& Slingerland, R.L. (1998) Origin of fluvial grain size trends in a foreland basin: the Pocono Formation of the central Appalachian Basin. J. Sediment. Res., 68, 473-486.

CrossRef | Web of Science ${ }^{\circledR}$ Times Cited: 42 | SFX

Romans, B.W., Normark, W.R., McGann, M.M., Covault, J.A. \& Graham, S.A. (2009) Coarse grained sediment delivery and distribution in the Holocene Santa Monica Basin, California: implications for evaluating source-to-sink flux at millennial timescale. Geol. Soc. Am. Bull., 121, 1394-1408.

CrossRef | CAS | Web of Science ${ }^{\circ}$ Times Cited: 32 | ADS | SFX

Seal, R., Paola, C., Parker, G., Southard, J. \& Wilcock, P. (1997) Experiments on downstream fining of 
CrossRef | Web of Science® Times Cited: 60 | SFX

Smalley, I.J., Kumar, R., O’Hara Dhand, K., Jefferson, I.F. \& Evans, R.D. (2005) The formation of silt material for terrestrial sediments: particularly loess and dust. Sed. Geol., 179, 321-328.

CrossRef | Web of Science® Times Cited: 28 | ADS | SFX

Sornette, D. (2006) Critical Phenomena in Natural Sciences, 2nd edn. Springer, Berlin.

SFX

Strong, N., Sheets, B.A., Hickson, T.A., \& Paola, C. (2005) A mass balance framework for quantifying downstream changes in fluvial architecture. Volume 35 of Fluvial Sedimentology VII, pp. 243-253. International Association Sedimentologists Special Publication.

Swinehart, J.B. \& Diffendal, R.F. (1987). Duer Ranch, Morrill County Nebraska: contrast between Cenozoic fluvial and eolian deposition, pp. 327-348.

Swinehart, J.B., Souders, V.L., DeGrew, H.M., \& Diffendal, Jr. R.F. (1985) Cenozoic paleogeography of western Nebraska. Society of Economic Paleontologists and Mineralogists, Rocky Mountain Section, Rocky Mountain Paleogeography Symposium 3.

Turcotte, D.L. (1997) Fractals and Chaos in Geology and Geophysics, 2nd edn. Cambridge University Press, Cambridge, UK.

CrossRef | SFX

Vincent, S.J. (2001) The Sis palaeovalley: a record of proximal fluvial sedimentation and drainage basin development in response to Pyrenean mountain building. Sedimentology, 48, 1235-1276.

Wiley Online Library | Web of Science® Times Cited: 51 | ADS | SFX

Weltje, G.J. (2012) Quantitative models of sediment generation and provenance: state of the art and future developments. Sediment. Geol., 280, 4-20.

CrossRef | Web of Science® Times Cited: 17 | ADS | SFX

Whittaker, A.C., Attal, M. \& Allen, P.A. (2010) Characterising the origin, nature and fate of sediment exported from catchments perturbed by tectonics. Basin Res., 22, 809-828.

Web of Science® Times Cited: 42 | SFX

Wolman, M.G. (1954) A method of sampling coarse river-bed material. Trans. Am. Geophys. Union, 35(6), 951-956.

Wiley Online Library ADS | SFX 